\title{
A MOÇÃO DE CENSURA EM PORTUGAL NOS ÚlTIMOS 35 ANOS, A SUA UTILIZAÇÃO COMO INSTRUMENTO POLITICO DE CONTROLO
}

\author{
Pedro Nunes \\ pnunes@ipca.pt \\ Instituto Politécnico do Cávado e do Ave \\ Conceição Castro \\ conceicaocastro@eu.ipp.pt \\ Instituto Politécnico do Porto
}

O presente artigo intenta plasmar o uso da moção de censura enquanto instituto de controlo político do Governo na actividade parlamentar portuguesa das últimas três décadas. Da análise às diversas legislaturas e sessóes legislativas dos vários governos constitucionais sistematizam-se aqueles mecanismos de controlo com referência à responsabilidade política do Governo.

Palavras Chave: moção de censura, moção de confiança, moção rejeição do programa do Governo, responsabilidade política.

\section{LA MOCIÓN DE CENSURA EN PORTUGAL EN LOS ÚLTIMOS 35 AÑOS, SU USO COMO INSTRUMENTO DE CONTROL POLÍTICO}

Este artículo pretende dar forma al uso de la censura como una institución de control político del gobierno portugués en la actividad parlamentaria de las últimas tres décadas. Se analizan las distintas legislaturas y sesiones legislativas de los diferentes gobiernos constitucionales para sistematizar los mecanismos de control en relación con la responsabilidad política del Gobierno.

Palabras clave: no-confidence motion, confidence motion, motion rejecting the government's program, political accountability. 


\section{INTRODUÇÃO}

De acordo com a componente parlamentar do regime misto instituído pela Lei Constitucional (doravante LC) de 1976, reforçada pela LC de 1982, o Governo é "responsável" perante a Assembleia da República (doravante AR) (Canotilho, 2003). Desse modo, o Direito procura condicionar a actuação do poder político quando fixa, na Constituição do Estado, os limites para o seu exercício. Burdeau sintetiza: "A Constituiçâo é o estatuto jurídico do poder" (Lobato, 2001) e, aqui, se trata a responsabilidade política. Uma situação de responsabilidade verifica-se quando um órgão ou o seu titular responde perante determinadas entidades pelos efeitos derivados do exercício de uma determinada actividade. A figura da responsabilidade assume diversas tipologias (responsbilidade penal, responsabilidade financeira, civil, etc.). Para o caso que nos ocupa, o da responsabilidade política, esta acontece quando deriva do facto dos efeitos do agente público se repercutirem na relação de confiança política que existe ou deva existir entre o titular do órgão em causa e o órgão que o propôs ou aceitou (cfr. com mais perfeição Canotilho, 2003:644). Esta conformidade (responsabilidade política), para além de abarcar uma responsabilidade parlamentar do Governo, implica também a responsabilidade solidária de todo o Governo perante a AR e não de uma responsabilidade individual dos ministros perante a mesma (Canotilho, 2003:644).

Não sendo propósito adiantar uma decomposição aprofundada dos vários modos de sistematização das funçôes da AR, importa aqui, mesmo assim, salientar que enquanto órgão constitucional de soberania, a $\mathrm{AR}$, e de acordo com o critério funcional, acomoda, as seguintes funções principais: (i) função electiva e função de criação de determinados órgãos; (ii) função de controlo e de fiscalização; (iii) função legislativa; (iv) função autorizante; e, (v) função de representação. É, de resto, a função de controlo e fiscalização a que importa para o presente trabalho, assumindo-se, como refere Canotilho (2003:635), como uma das mais importantes funçôes da AR. Em especial, interessará, dentro deste arranjo ou subespécie, a função controlo e não a função fiscalizadora, uma vez que é daquela, e não desta, que decorre o acto típico de controlo, como: perguntas e interpelaçóes; inquéritos; petiçōes; e, as moçôes de censura.

A existência de uma relação fiduciária entre órgãos de soberania (neste caso o Governo e a AR), visível pelo controlo e responsabilidade (política, para o caso que 
nos comete), acarreta uma interdepêndencia institucional entre aqueles órgãos, repousando a responsabilidade politica do Governo perante a AR no poder que esta detém de retirar àquele órgão a confiança política que carece para governar. Segundo Gomes Canotilho (2003:605) o desencadeamento da responsabilidade política do Governo pode ter como base: (i) uma questão de confiança, traduzida na iniciativa do Governo em sujeitar a sua permanência em funçóes a um voto da $\mathrm{AR}$, geralmente relacionado com a aprovaçáo do programa ou com uma declaração de política geral deliberada em Conselho de Ministros; e, (ii) uma iniciativa dos deputados (1/4 dos deputados em efectividade de funçôes) ou dos grupos parlamentares através de moçóes de censura.

Assim, transcorre do art. ${ }^{\circ} 194 .^{\circ}$ da LC (2005) que a Assembleia da República pode votar moçóes de censura ao Governo sobre a execução do seu programa ou assunto relevante de interesse nacional, por iniciativa de um quarto dos Deputados em efectividade de funçóes ou de um grupo parlamentar. Acresce, ainda, que as moçôes de censura só poderão ser apreciadas quarenta e oito horas após a sua apresentação, em debate de duração não superior a três dias e que se a moção de censura não for aprovada, os seus signatários não podem apresentar outra durante a mesma sessão legislativa. Sobrevém, portanto, que a figura jurídica da moção de censura, enquanto instrumento de controlo e, em particular, da actividade do Governo, pode mesmo implicar, no caso de ser aprovada por maioria absoluta dos Deputados em efectividade de funções, a demissão do Governo.

Outras figuras jurídicas potenciam, ou pelo menos asseguram, o controlo da actividade parlamentar, como sejam a Pergunta, o Requerimento (previstas quer na Constituição da República Portuguesa - doravante CRP, quer no Regimento da Assembleia da República, doravante RAR), os Inquéritos Parlamentares, as Petiçôes, a Interpelação ao Governo, o Debate sobre o Programa do Governo, Apreciação e aprovação da Conta Geral do Estado, Relatórios de Entidades Exteriores, Apreciação de Decretos-Lei, etc. Nesta prossecução, o princípio parlamentar abrangerá em si e na sua essência o controlo político do Governo pelo parlamento, "cujo instrumento mais radical" (Canotilho, 2003:638) é a moção de censura ("máximo instrumento sancionador da responsabilidade política”, Montero, 1979), que se cuidará sistematizar para o caso português, nestas breves reflexóes.

Apesar da existência de alguma confusão entre a instituição do juízo politico (comum nos chamados sistemas presidenciais puros) e a própria censura (própria 
dos que têm matriz parlamentar e, sobretudo, dos sistemas parlamentarizados (Zovatto et al, 2007) tratar-se-á, a moção de censura, aqui, essencialmente como um mecanismo de controlo ocorrido nos sistemas constitucionais parlamentares.

\section{MoÇÃO DE CENSURA: CONCEPTUALIZAÇÃo}

Apesar das críticas suscitadas pelo seu mimetismo, escassa originalidade e até copista, a história constitucional europeia do século XIX está repleta de situações similares e, para o século XX, confirmando-se que a "técnica constitucional do parlamentarismo não dispóe de muito meios", de modo que, "cada vez que se buscam as melhores formas do funcionamento democrático, se cai fatalmente nas mesmas fórmulas de lógica jurídica" (Montero, 1979), sendo que os conceitos políticos são instrumentos do pensamento teórico, mas também próximos dos fins políticos, das tomadas de posição, etc. "A 22 de Março de 1881, Fontes apresentava na Câmara dos Pares uma moção de censura. Dois dias depois, o governo caía" (Mónica, 1996). Como se sabe, não é novo o instituto da moção de censura. Apesar dessa condição, o artigo intenta, apenas, encarregar-se da conceptualização daquele mecanismo, quer na sua conceptualização, quer o seu uso na actividade parlamentar, essencialmente nos pós 25 de Abril (periodo democrático).

Desse modo e se, por um lado, na década de 70 o controlo parlamentar funcionava como uma garantia da democracia (mediante a mera prescrição de instrumentos solenes e irregulares, como as interpelaçóes ou as moçóes de censura), por outro, a partir de finais dos anos 80 o controlo parlamentar tornou-se uma prática da democracia (Leston-Bandeira, 2000) que em paralelo com o crescimento do Estado social e o seu progressivo alargamento a quase todas as áreas da actividade humana fizeram com que a capacidade de intervenção dos parlamentos, mesmo por via legislativa, se afunilasse progressivamente (Vitorino et al, 2000) ficando (...) refém de um progressivo alargamento das competências legislativas do executivo (idem, 2000), assitindo-se, segundo autor, à decrepitude de um parlamento que náo soube agilizar as suas competências e que sobrevive à custa de momentos rituais, como a discussão do Orçamento de Estado, e que pode ser marginalizado por um primeiro-ministro que domine uma maioria absoluta parlamentar e que se escuse ao debate político. Neste contexto podem distinguir-se três tipos de 
controlo parlamentar (Mény, 1996:121): (i) controlo partidário (partisan control), com voz na oposição, com condiçóes de eficácia nas situaçóes em que o governo se encontra mais vulnerável; (ii) controlo não partidário (non-partisan control), por meio de controlo parlamentar, por exemplo perguntas, interpelaçóes, audiçóes, etc., e, (iii) controlo com penalidade (control with a penalty), como a moção de censura, que é a figura mais drástica e que pode, até, desestabilizar o sistema (Pennings, 2000). A AR pode tipificar-se, no processo legislativo, de acordo com os termos desenvolvidos por Philip Norton: (i) parlamento influenciador (policy-influencing) - ou seja, que consegue modificar e rejeitar as medidas apresentadas pelo executivo, mas não consegue substituí-las pelas suas próprias propostas; (ii) parlamento produtor (policy-making) — ou seja, que consegue modificar e rejeitar as medidas apresentadas pelo executivo, assim como substituílas pelas suas próprias propostas; e, (iii): parlamento com pouco ou nenhum impacto no processo legislativo (legislature with little or no policy affect) — ou seja, que não consegue nem modificar ou rejeitar as medidas apresentadas pelo governo nem substituí-las pelas suas próprias propostas (Leston-Bandeira, 2000). Apesar disso, é comum encontrar, de um modo geral, três tipos de intrumentos que agem como testes de confiança no Governo: moçöes de confiança (confidence motions) ${ }^{1}$ de inciativa governamental, moçōes de censura (no confidence motion) lançadas pela oposição e outros instrumentos que, devido a circunstâncias particulares podem ser considerados como moçôes de censura ou confiança (Kelly et al, 2010).

Para Portugal, e como expressão da responsabilidade política do Governo perante a $\mathrm{AR}$, própria da actividade parlamentar do sistema de governo semipresidencialista (Rebelo de Sousa et al, 2000) a moldura da moçâo, enquanto um instrumento político de controlo, comporta as seguintes tipologias: (i) Moção de censura,

1 As moçoes de confiança têm um papel constitucional fundamental uma vez que por um lado não são raras as vezes dessa perda, e por outro, obrigam o partido do governo a defender e explicar as suas políticas aos partidos da oposição e, através deles, ao país como um todo (Brazier, R, 1994, Constitutional Practice, 2nd ed. pp.212-13, apud Kelly et al, 2010). A diferença fundamental entre uma moção de censura e uma moção de confiança é que a primeira contempla o passado - a que pretende pôr termo - enquanto a moção de confiança representa uma aposta sobre o futuro. A razão pela qual o Governo utilizou o mecanismo da moção de confiança e, voluntariamente, se submete ao veredicto da Assembleia. Um voto de confiança (moçáo de confiança) é a facultade de solicitar à oposição um voto de confiança no Governo (Segado, 1987). 
que visa reprovar a execução do Programa do Governo ou a gestão de assunto de relevante interesse nacional. Pode ser apresentada por um quarto dos Deputados em efectividade de funçóes ou por qualquer grupo parlamentar; (ii) Moção de confiança, que visa aprovar um voto de confiança sobre uma declaração de política geral ou assunto de relevante interesse nacional. É apresentada pelo Governo e a sua rejeição simples provoca a demissão do Governo; e, (iii) Moção de rejeiçáo do Programa do Governo, que constitui um direito exclusivo dos grupos parlamentares. A sua aprovação requer uma maioria absoluta dos Deputados em efectividade de funçōes e provoca a demissão do Governo.

Através da moção de censura (de iniciativa parlamentar, a contrário da moção de confiança que é de inicitiva governamental) a AR "póe em jogo" (Canotilho, 2003:638) a responsabilidade política do Governo, uma vez que, como se disse, a sua aprovação implica a demissão daquele órgão. $\mathrm{O}$ controlo material dirige-se, assim, segundo aquele autor (idem, ibidem): (i) à fiscalização dos resultados da actividade legislativa; e (ii) à fiscalização das vias e fins da política governamental. É também encarado como um controlo pessoal na dimensão em que pode pôr em causa a capacidade política do Primeiro-Ministro (doravante PM) e, indirectamente, dos seus ministros, para levarem a cabo determinada política.

Apesar da responsabilidade ser solidária de todo o Governo perante a AR e não de uma responsabilidade individual como supra se referiu para o caso português, sistemas há em que, da interpretação de diferentes perspectivas do problema (do ponto de vista constitucional) tal conexão oferece perfis ambíguos, isto é, a moção de censura, ou moções de reprovação, poderão intentar, nalguns sistemas constitucionais substituir a inexistencia de uma responsabilidade politica individual constitucionalmente exigivel dos ministros em exercício de funçôes (Asensio, 2001).

Solé Tura referia-se à faculdade da moção de censura como "um dos problemaschave com que se defronta o sistema parlamentar moderno", estimando-se que se está "em presença de um dos artigos mais importantes (...) da Constituição" apud Montero (1979), embora se entenda este realce, não se deve ofuscar outros mecanismos de controlo igualmente previstos na Constituiçáo e que, para o caso português são, até, usados com maior frequência que a própria moção de censura (cfr. número de moçôes de rejeição do programa do governo, tabelas 2 , 3 e 6) sendo que a moção de rejeição do programa do Governo (para o caso português) 
ultrapassa, no número de vezes em que é utilizada, em período democrático, o da moção de censura, não se passando da mesma forma com a moção de confiança, usada por escassas vezes.

A moção de censura, também conhecida por votes of no-confidence (Bergman, 1993; Powell, 2004; Maskell, 2007; Heard, 2007)² é, talvez, dos procedimentos parlamentares mais importantes, embora esteja, na maioria das vezes, dependente de maiorias absolutas, para produzir o efeito desejado. Este procedimento ou mecanismo de controlo da actividade política do Governo e da consequente possibilidade de lhe contestar responsabilidade (Portero, 1998) vem ganhando espaço na actividade parlamentar, embora para muitos seja recorrente a discussão da introdução da moção de censura construtiva, como modelo mais perfeito.

\subsection{A MOÇÃO DE CENSURA CONSTRUTIVA}

Foi Fraenkel (1932, apud, Foruria, 1987) quem porpôs a fórmula definitiva da moção de censura construtiva que conhecemos hoje. A característica principal desta moção de censura é a obrigação de se apresentar um candidato para responsabilidades governativas (presidente do governo, primeiro-ministro, conforme o sistema). O designativo de construtiva deriva de que a sua proposta e votação no parlamento há-de incluir uma proposta e votação simultânea de um candidato a presidente ou primeiro-ministro do Governo (Salgado, 1998).

A Constituição da República Portuguesa não consagra, na moldura da moção, a figura da moção de censura construiva (como fazem a Alemanha, Espanha, Japão,

2 Embora a expressão vote of no confidence seja geralmente usada nos Estados Unidos para descrever o processo, no Reino Unido, refere-se à votação pela oposição, designada por vote of censure. Um vote of no confidence (or censure) é um voto em que se determina, ou não, se um Governo no poder é, ainda, tolerado pelo parlamento (Bergman, 1993). Contudo, nos parlamentos democráticos os arranjos técnicos para este tipo de votação variam consideravelmente. Termos como voto de confiança e moção de censura são considerados, muitas vezes, aproximadamente sinónimos, quando se referem, na sua votação à possibilidade de remoção do Governo, sendo que as modalidades técnicas de tal votação variam consideravelmente. Por exemplo, em algumas democracias parlamentares náo existe um instrumento formal, como o voto de confiança. Nessas democracias supóe-se que um Governo deva renunciar se perde uma votação sobre um tema de grande importância. Na Dinamarca, Finlândia e Noruega, o voto de confiança não tem esta configuração (Bergman, 1993). 
Suécia, Bélgica, Itália, Israel, etc. ${ }^{3}$ ) embora o seu discurso no Parlamento não seja novo. Aliás, nas sessóes legislativas onde se procede ao debate de apresentaçáo, e nos períodos seguintes, da moção de censura, a figura da moção de censura construtiva é um assunto recorrente. Aquando da quarta revisão constitucional o projecto do Partido Socialista propunha a consagração do instituto da moção de censura construtiva (Vitorino et al, 2000:296). Esta consagração está, segundo António Vitorino (idem, 2000) relacionada com o aparecimento de coligaçóes negativas que tornam ainda mais premente o aperfeiçoamento dos mecanismos de racionalização nas relaçôes entre o parlamento e o governo, em particular os mecanismos de confiança alternativa (...) podendo fazer coincidir os mecanismos de confiança alternativa com a moção de censura construtiva.

Para além desta recorrência, em séde de discussão e debate parlamentar, os partidos ${ }^{4}$ políticos (veja-se o exemplo do PS e do PPD-PSD, em diferentes momentos) incluíram nos seus programas eleitorais a defesa daquele instituto de controlo.

Como modo de assegurar a continuidade num Governo, o método parece especialmente válido (Montero, 1979), embora alguns autores assim o não considerem (Foruria, 1987) quando referem que a moção de censura construtiva não proporciona estabilidade governamental, ao depender, aquela, de outros factores. Pode, isso sim, fomentar intrigas contra o Governo no poder, favorecer a continuidade de Governos minoritários inabaláveis por maiorias parlamentares. Embora Montero (1987) assuma, argumentando-se aqui em seu apoio, que a estabilidade, no plano teórico, possa ocorrer mas que, já no plano prático a moção de censura construtiva queda-se quase impossível, como o demonstra a experiência

3 Note-se que nestas situaçóes, desiguais, existem particularidades muito especiais como o caso da Bélgica. Assim, o país, mesmo com sistema de governo diferente, poderá ter, em relação à moção de censura construtiva, também requisitos diferentes (sujeito da censura, número mínimo de proponentes, forma de apresentação, prazo, votaçáo, etc.).

4 O PS incluíra a defesa da moção de censura construtiva nos programas eleitorais de 1985 e de 1987. Sobre a sua posição nesta matéria para a segunda revisão, cf. A Revisão Constitucional e a Moção de Censura Construtiva, Lisboa, Fundação Friedrich Ebert, 1988. O projecto apresentado, em 1979, por Sá Carneiro prevê o mecanismo da moçáo de censura construtiva, tal como o projecto de alteraçóes preparado por Pedro Santana Lopes. Todavia, o projecto preparado por instrução do coordenador da Aliança Democrática rejeita expressamente este mecanismo, por o considerar contrário à "essência do sistema de governo semipresidencial". Não obstante, o projecto oficial da Aliança Democrática volta a adoptar a moção de censura construtiva. Cfr. Francisco Sá Carneiro, op. cit., pp. 129, Pedro Santana Lopes, op. cit., p. 214, A. Barbosa de Melo, op. cit., pp. 228-229, Projecto de Lei de revisão constitucional n. ${ }^{\circ}$ 2/II, loc. cit., artigo 197. ${ }^{\circ}$ apud Gaspar, 1990. 
Alemá, pela dificuldade dos partidos da oposição se colocarem de acordo sobre a apresentaçáo de um candidato alternativo à presidência do Governo (Montero, 1979). Apesar disso, e das diversas soluçóes teóricas e prácticas que se foram idealizando na Alemanha durante os anos vinte e trinta, aquele país acaba por adoptar o que veio a denominar-se de moção de censura construtiva (Foruria, 1987, p.100). Para Salgado (1998) um dos factores institucionais mais importantes, concebidos pelos agentes políticos, capaz de influir e modelar o formato do sistema de partidos, é a moção de censura constructiva (os outros dois são, segundo o autor, o sistema eleitoral e a descentralização política). Apesar dos argumentos, contra e a favor, ainda hoje (veja-se as últimas declaraçóes públicas do presidente do PSD, Pedro Passos Coelho, ao vir a público defender o instituto da moção de censura construtiva, na futura revisão constitucional) se mantém, facto já defendido pelo PS ( $c f r$. textos das sessóes legislativas, de 5 de Fevereiro de 1982, pp. 1020 e ss.) na voz de António Vitorino quando referia "O projecto do PS salvaguarda cuidadosamente o equilíbrio e a separação de poderes caracterizadores de um regime semipresidencialista e insiste no aperfeiçoamento dos mecanismos da governabilidade e estabilidade política, através da consagração da moção de censura construtiva, como factor de estabilidade e de alternância (artigo 197. ${ }^{\circ}$ ) ".

A questáo da moçáo de censura, sempre retomada, como se referiu, particularmente em momentos que antecedem, ou se preveja venha a fazer-se uma revisão constitucional, tem-se mantido atacada e não tem alcançado os dois terços necessários para passar ao texto constitucional.

\section{Os motivos da moçáo de censura em Portugal}

A engenharia constitucional deve, pois, assegurar o bom relacionamento entre os poderes do Estado (Lobato, 2001). É esta, aliás, a filosofia da generalidade dos sistemas administrativos. As relaçóes entre o executivo (Governo) e o legislativo (Parlamento), (embora o Governo também possua competência legislativa no caso Português) são caracterizdas por 3 situaçóes: (i) situação em que os parlamentos dominam o governo; (ii) situação em que o Governo domina o parlamento; e, (iii) situação em que predomina um equilíbrio de poder, como é, de resto, a posição portuguesa (tabela 1). 


\section{Tabela 1: Variaçóes no equilíbrio de poder entre executivo e legislativo}

\begin{tabular}{l|l|l}
$\begin{array}{l}\text { Parlamento domina } \\
\text { o Governo }\end{array}$ & \multicolumn{1}{|c|}{ Equillibrado } & \multicolumn{1}{|c}{ Governo domina Parlamento } \\
& $\begin{array}{l}\text { Austrália, Áustria, Bulgária, Canadá, } \\
\text { República Checa, Dinamraca, Estónia, }\end{array}$ & $\begin{array}{l}\text { Bangladesh, Bélgica, Botswana, } \\
\text { Grécia, Irelanda, Itália, Jamaica, }\end{array}$ \\
$\begin{array}{l}\text { Alemanha, Hungria, } \\
\text { Israel, Macedónia }\end{array}$ & $\begin{array}{l}\text { Japáo, Letónia, Luxemburgo, Malta, } \\
\text { Holanda, Noruega, Polónia, Portugal, Guiana, Islândia, } \\
\text { Roménia, Russia, Eslováquia, } \\
\text { Eslovénia, África do Sul, Espanha, Lituânia, Namíbia, Nova } \\
\text { Suiça }\end{array}$ & $\begin{array}{l}\text { Zelândia, Paquistáo, Sri Lanka, } \\
\text { Suécia, Turquia, Reino Unido, } \\
\text { Estados Unidos da América }\end{array}$ \\
\hline
\end{tabular}

Fonte: Pennings, 2000. Tradução própria.

A relação do Governo com Parlamento adquire, assim, uma matriz específica no sistema parlamentar uma vez que o Governo se estabelece e mantém na relação de confiança com o Parlamento (Segado, 1987). Trata-se de uma coesão ou negação (idem, 1987) dessa mesma confiança cuja manifestação mais forte poderá traduzir a saída do Governo, posição que será sempre mais fragilizada se o Governo estiver em minoria. Com o aparecimento de governos maioritários assiste-se à proliferaçáo dos mecanismos de controlo parlamentar que possam marcar a agenda política, nomeadamente os debates de urgência e as comissóes de inquérito parlamentar, e à diminuição do recurso aos mecanismos menos mediáticos, em particular o número de requerimentos dirigidos pelos deputados ao governo (Vitorino et al, 2000:297). Embora se constacte que a flutuação eleitoral portuguesa seja substancialmente superior à média europeia (Matos, 1992:776), um dos aspectos mais notáveis deste processo prende-se com a diminuição do grau de fidelidade entre o eleitorado e os vários partidos, definido em muitos estudos como analisável a partir de um grau de volatilidade do voto (Vitorino et al, 2000:277). A propósito desse facto, o autor (idem, 2000:283) argumenta que à escala macro, o sistema partidário português apresenta um elevado grau de estabilidade, continuando centrado em torno dos quatro partidos fundadores do regime democrático, com dois partidos que disputam o centro e exercem o poder e dois partidos minoritários que, em coligação expressa ou mediante acordos parlamentares pontuais, participam pontualmente no exercício desse poder.

$\mathrm{Na}$ praxis política portuguesa posterior ao 25 de Abril foram experimentadas todas as combinaçôes possíveis, com excepção de duas (Vitorino et al, 2000:295): assim, existiram (i) governos maioritários monopartidários e de coligação, de coligação 
pré-eleitoral e de coligação pós-eleitoral; (ii) governos minoritários monopartidários $e$ de coligação; (iii) governos com apoio do Presidente da República e de iniciativa do Presidente da República; (iv) coabitação entre governos e presidentes de diversas origens politicas; (v) coexistência de um governo e de um presidente da República da mesma cor política. Resta ainda o aparecimento de um presidencialismo de base partidária dominado por um presidente da República que seja o efectivo líder do partido maioritário e que a partir do palácio de Belém controle o executivo por intermédio de um primeiro-ministro complacentes.

Sendo que a actividade parlamentar se divide, essencialmente, sob dois grandes títulos: legislação $0^{6}$ e fiscalização. É neste segundo aspecto, como já se referiu, que intervém, com todas as consequências daí advindas, o instituto clássico de controlo parlamentar ${ }^{7}$, que no caso português, se trata de uma competência política crucial da AR. O governo é politicamente responsável perante a AR, pelo que, de acordo com a Constituição, deve mantê-la informada sobre a acção governativa e da administração pública. Assim a moldura da moção (censura ou confiança), tal como se caracterizou na introdução, ao materializar-se numa aprovação ou rejeiçâo, respectivamente, provocará a demissão do Governo.

Como toda a Constituição moderna, a Constituição Portuguesa adopta uma série de cautelas a fim de evitar a apresentação abusiva das moçóes de censura, a sua tramitação e a sua possível aprovação, quórum, etc., uma vez que o controlo constitui uma actividade que um sujeito (controlante) exerce sobre outro (controlado) para a tutela de certos valores que o primeiro tem o dever de proteger, actividade que pode consistir na verificação se foram respeitados os valores e os princípios protegidos e a adopção de medidas sancionatórias e correctivas, em caso contrário (Santaolalla López, 1990:240). O controlo parlamentar é uma lógica consequência da existência de uma relação básica que liga de forma directa e

5 Historicamente, parece ter sido esse o desejo, na versão mais ambiciosa, que esteve na origem do Partido Renovador Democrático, patrocinado por Ramalho Eanes enquanto ainda era presidente da República. Alguns comentadores políticos apontaram a Mário Soares idêntico propósito frustrado por uma coabitação difícil que se estendeu até Outubro de 1995) (Vitorino et al, 2000:295).

6 O processo legislativo integra quatro fases deliberativas. Uma vez apresentado, um diploma é enviado para $\mathrm{a}(\mathrm{s})$ comissão(óes) competente(s), a(s) qual(is) elabora $(\mathrm{m})$ um parecer de apreciaçâo para subir à generalidade (Leston-Bandeira, 2000).

7 A Constituição contém, ainda, um conjunto de institutos de fiscalização, tal como as as interpelaçôes, as comissóes de inquérito, e as perguntas ao governo. 
indesculpável ao Governo com o Parlamento no regime parlamentar, traduzindo que o "poder é uma força ao serviço de uma ideia" (Burdeau, apud Lobato, 2001). Apesar disso, há indicadores de que no Parlamento Português há um alto grau de tolerância (e liberdade) para construir o discurso sem a intervenção censuradora do presidente (Matos, 1992:294).

\section{Tabela 2: n.o moçóes/partido}

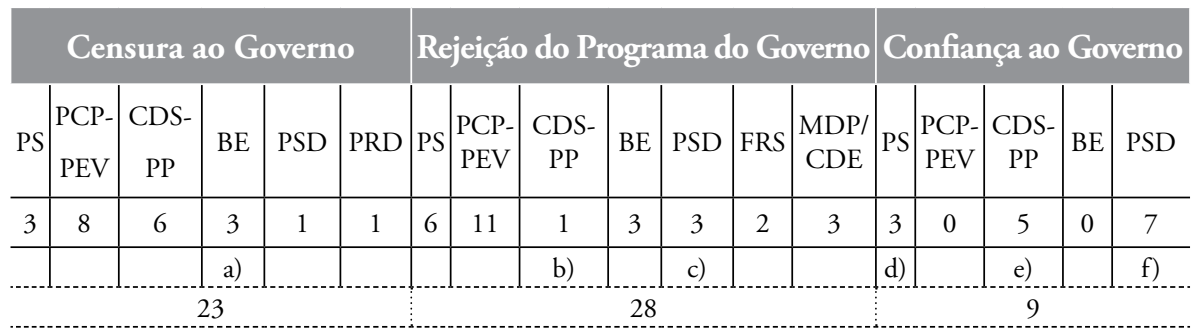

Fonte: www.parlamento.pt, construção própria a) Dever-se-á considerar que é um partido apenas formado em 1985; b) uma com PSD; c) uma com CDS; d) uma com PSD; e) cinco com PSD; f) cinco com CDS e uma com PS.

Nas últimas três décadas (33 anos em particular) de actividade parlamentar, nas várias legislaturas e sessões legislativas, a moção de censura ao Governo ( $c f r$. tabela 2) foi usada em 51 momentos: 23 vezes na moção de censura ao Governo, 28 vezes na moção de rejeição ao Programa do Governo. Foram ainda apuradas 9 moçôes de confiança ao Governo (tabela 2). O primeiro grande impacto do uso da moção da censura terá sido, talvez, a 3 de Abril de 1987 quando se aprovou uma moção de censura ao governo, de iniciativa do PRD. Naquela ocorrência a

Assembleia foi dissolvida e as eleiçóes de 19 de Julho deram lugar à primeira maioria absoluta do PSD. A primeira da nossa história democrática (LestonBandeira, 2000). 
Grafico n. ${ }^{\circ}$ : tipo de moçáo/ Autorn/n.o vezes em que foi usado o instituto de controlo - 1977-2010

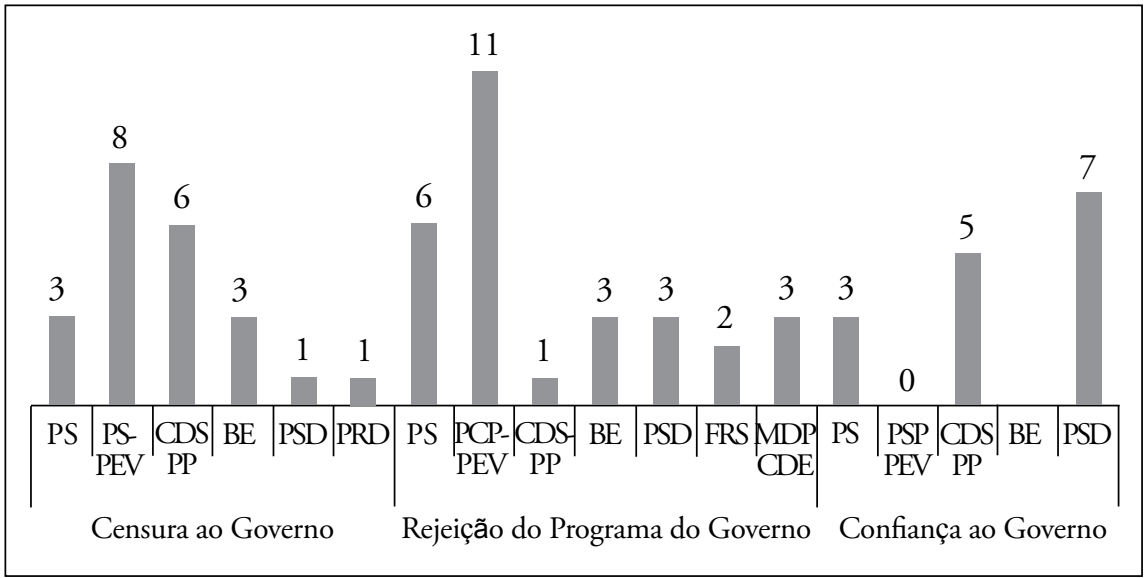

A análise dos institutos de controlo na moldura da moção, permitem concluir que:

i. Do total das moçóes de confiança, o PPD-PSD é o partido que mais usou esse mecanismo (85,7\%), sózinho ou em coligação com o CDS-PP e uma vez com o PS;

ii. O PS usou o mecanismo da moçáo de confiança apenas 3 vezes, sendo que uma delas foi em Governo com o PSD;

iii. A moção de confiança é um instituto usado essencialmente à direita do espectro partidário (85,7\%), onde se inclui o PPD-PSD, CDS-PP e o PPM;

iv. A moçáo de confiança é usada essencialmente quando os partidos estão em maioria, quer de um só partido, quer em coligação, sendo o instituto de controlo menos usado;

v. Do total das moçóes de confiança apenas uma foi rejeitada;

vi. A moçáo de rejeiçáo do programa do Governo é dos três institutos de controlo a mais usada na moldura da moção $(46,4 \%)$, seguido da moçáo de censura com $41 \%$ e da moçáo de confiança com $12,5 \%$;

vii. Do total das moçóes de rejeição do programa do Governo, o PCP (com o PEV) é o partido que mais usou esse mecanismo $(38,4 \%)$, seguido do PS com 19,2\%, o PSD com 11,5\%; 
viii. A moção de rejeição do programa do Governo é um instituto usado essencialmente à esquerda do espectro partidário $(88,4 \%)$, onde se inclui PCP-PEV, PS, MDP-CDE, BE e FRS;

ix. Do total das moçóes de rejeição do programa do Governo, apenas uma foi aprovada;

x. Do total das moçóes de censura, o PCP-PEV é o partido que mais usou esse mecanismo (34,7\%), seguido pelo CD-PP com $26 \%$, o BE e PS com $13 \%$ cada, PSD e PRD com 4,3\% cada um;

xi. A moção de censura ao Governo é um instituto usado mais à esquerda $(69,5 \%)$ do que à direita $(30,4 \%)$ do espectro partidário; e,

xii. Do total das moçóes de censura ao Governo, apenas duas foram aprovadas.

Os motivos ou, em última instância, o que motiva a apresentação de uma moção de censura, têm sido, nos últimos anos, objecto de muitos estudos académicos. De um modo geral aparecem do geral para o particular, isto é, por norma é dado um título à moção, que para o caso português (salvo excepçôes de motivos de segurança e guerra) assume as seguintes designaçóes: (i) censura ao Governo sobre a execução do seu programa; (ii) pelas políticas adoptadas em diversos sectores da vida portuguesa; (iii) política global do Governo; (iv) condução da política governativa; (v) Resultado das eleiçôes X ou Y; (vi) estabilidade politica, progresso social e consolidação da democracia; (vii) Futuro do país; e, (viii) crescimento e desenvolvimento económico (ausência); etc. etc.

Da leitura dos milhares de páginas no período compreendido entre 1979 e 2010, das várias lesgislaturas e dezenas de sessóes legislativas, onde se compreendem milhares de diários da AR, pode perceber-se que a grande maioria das moçóes de censura partem, ou são motivadas, por um fénomeno ou facto em concreto (uma participção do Governo na Guerra, um resultado eleitoral, um motim, ou uma greve geral) para servir de mote à censura e, aquando da apresesentação da moção, esta discorre, fundamentalmente para assuntos correntes. Daqui não se pressupóe que esses mesmos assuntos sejam de somenos importância, até porque, na generalidade, pelas observaçóes feitas, comprovaram-se os seguintes 
motivos: (i) dificuldades económicas e financeiras do pais; (ii) pluralismo dos órgãos de comunicação social; (iii) pacote laboral; (iv) a regionalização; (v) operaçôes de desestabilização das forças armadas; (vi) greve geral; (vii) desemprego e inflação; (viii) instrumentalização política de populaçôes; (ix) crédito à habitação; (x) privilegiar clientelas políticas; (xi) dificuldades no acesso ao mercado do trabalho; (xii) escândalos e rumores de vária ordem; (xiii) aumentos salariais e de reforma (ausência); (xiv) sistema de saúde; (xv) contas públicas e elevados défices; (xvi) grandes obras e aquisiçôes como TGV, submarinos, Euro 2004, aeroporto, etc.; e, (xvii) SCUTS, etc.

Do que se trata aqui, embora não seja presente o objectivo de uma análise profunda dos motivos, é da ausência de discurso ideológico, que de certa corroboraria a ideia de que a "função de controlo agia enquanto garantia da democracia, e não enquanto prática da democracia" (Leston-Bandeira, 2000:197). 


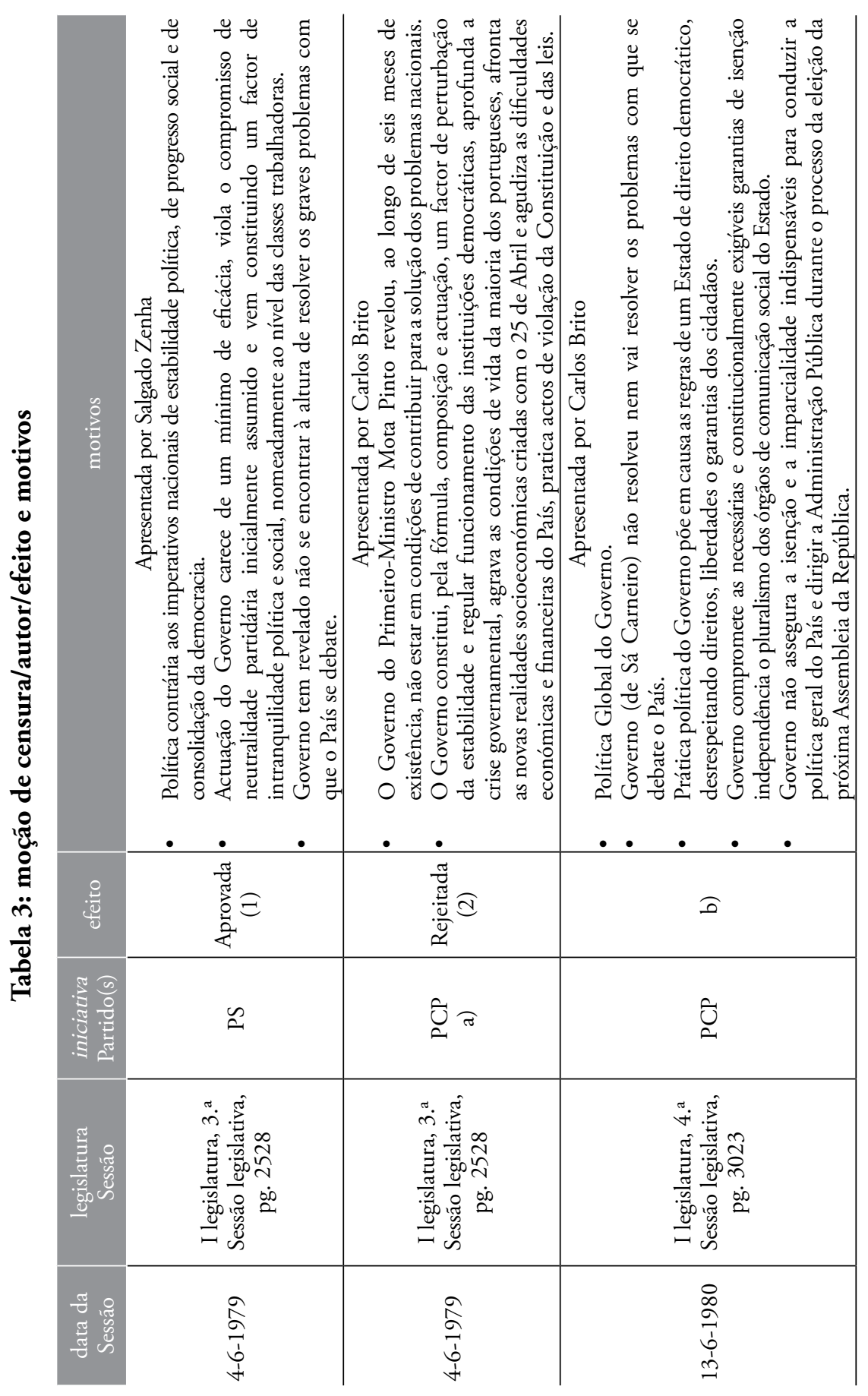




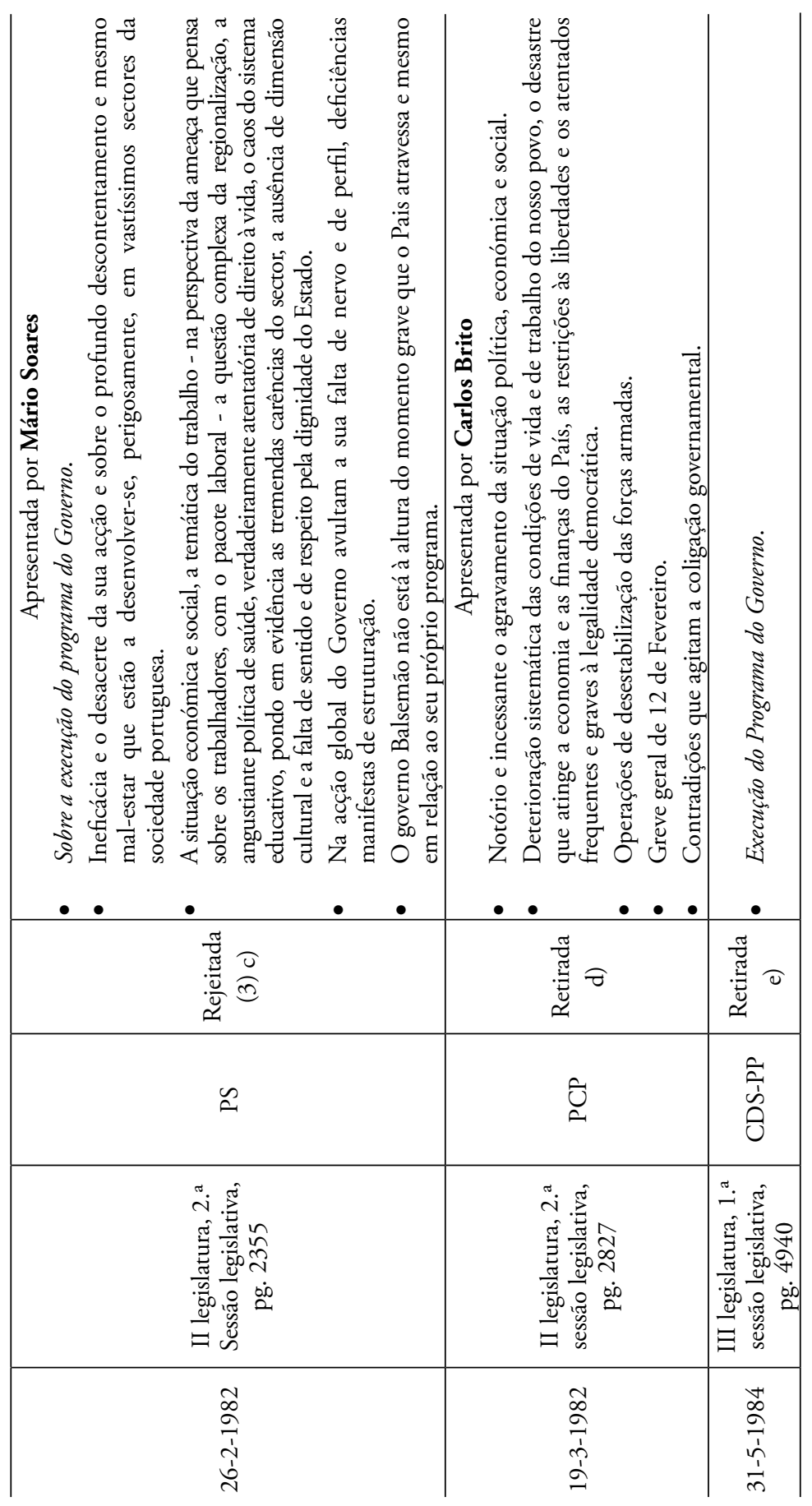




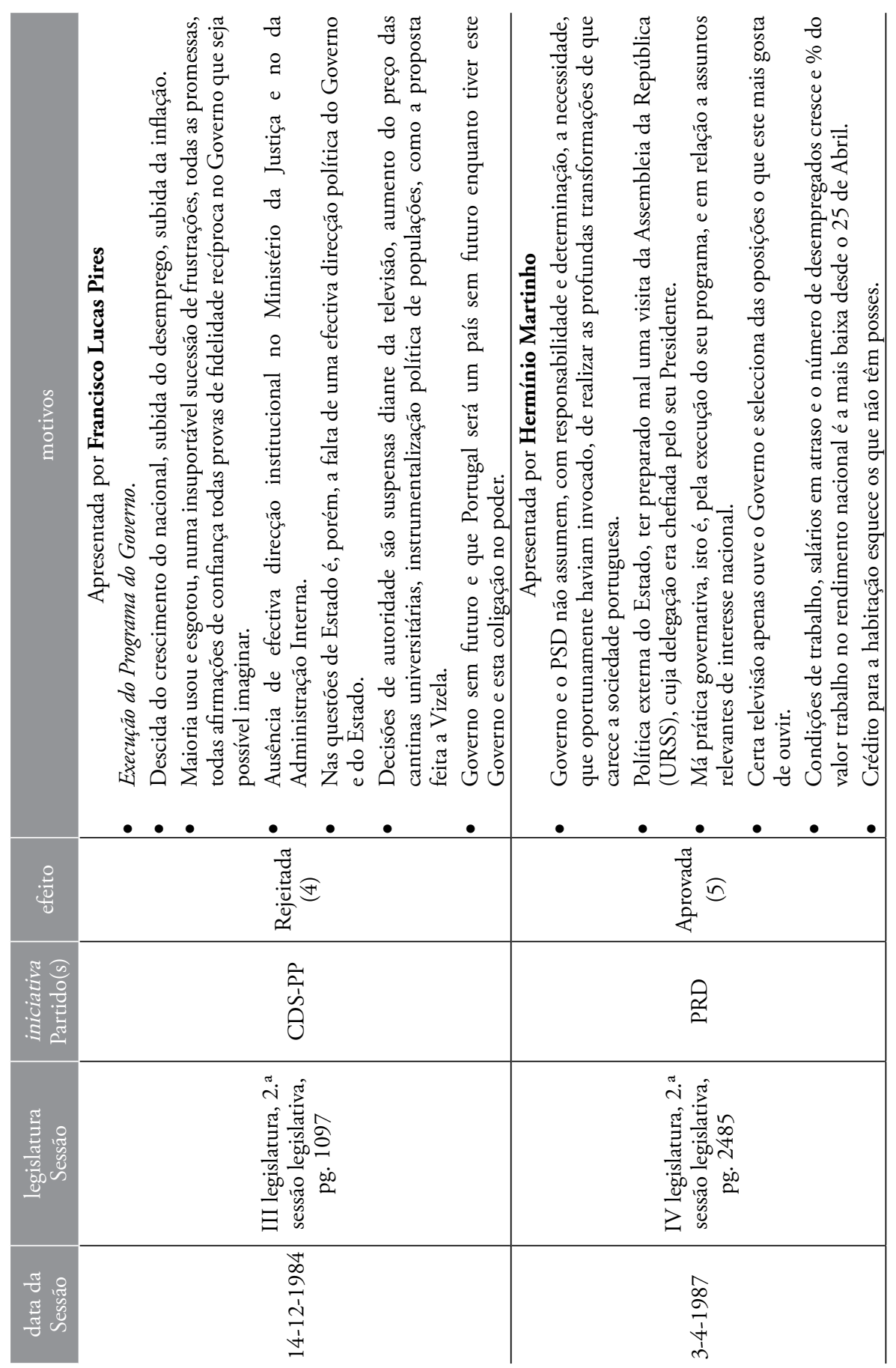




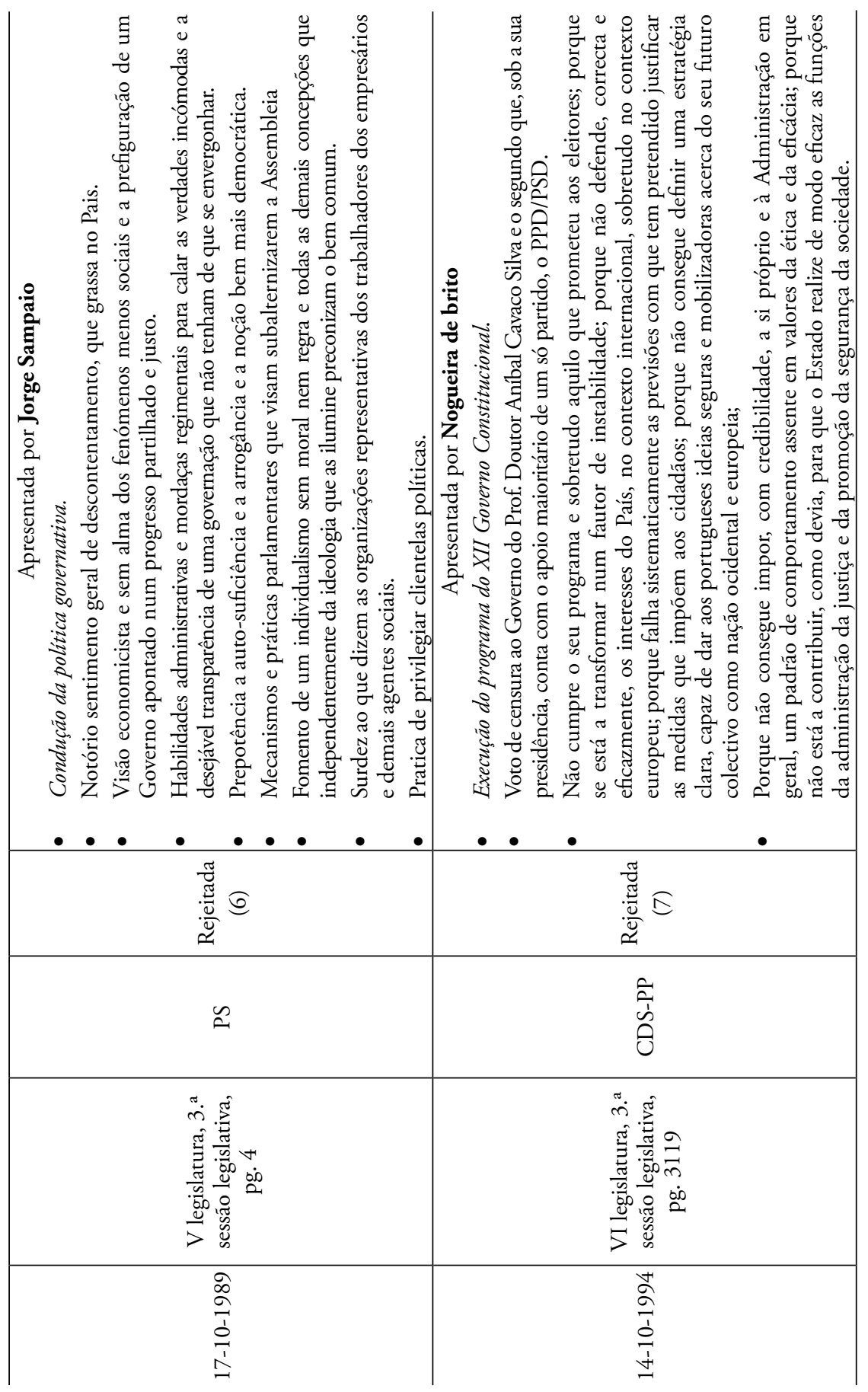




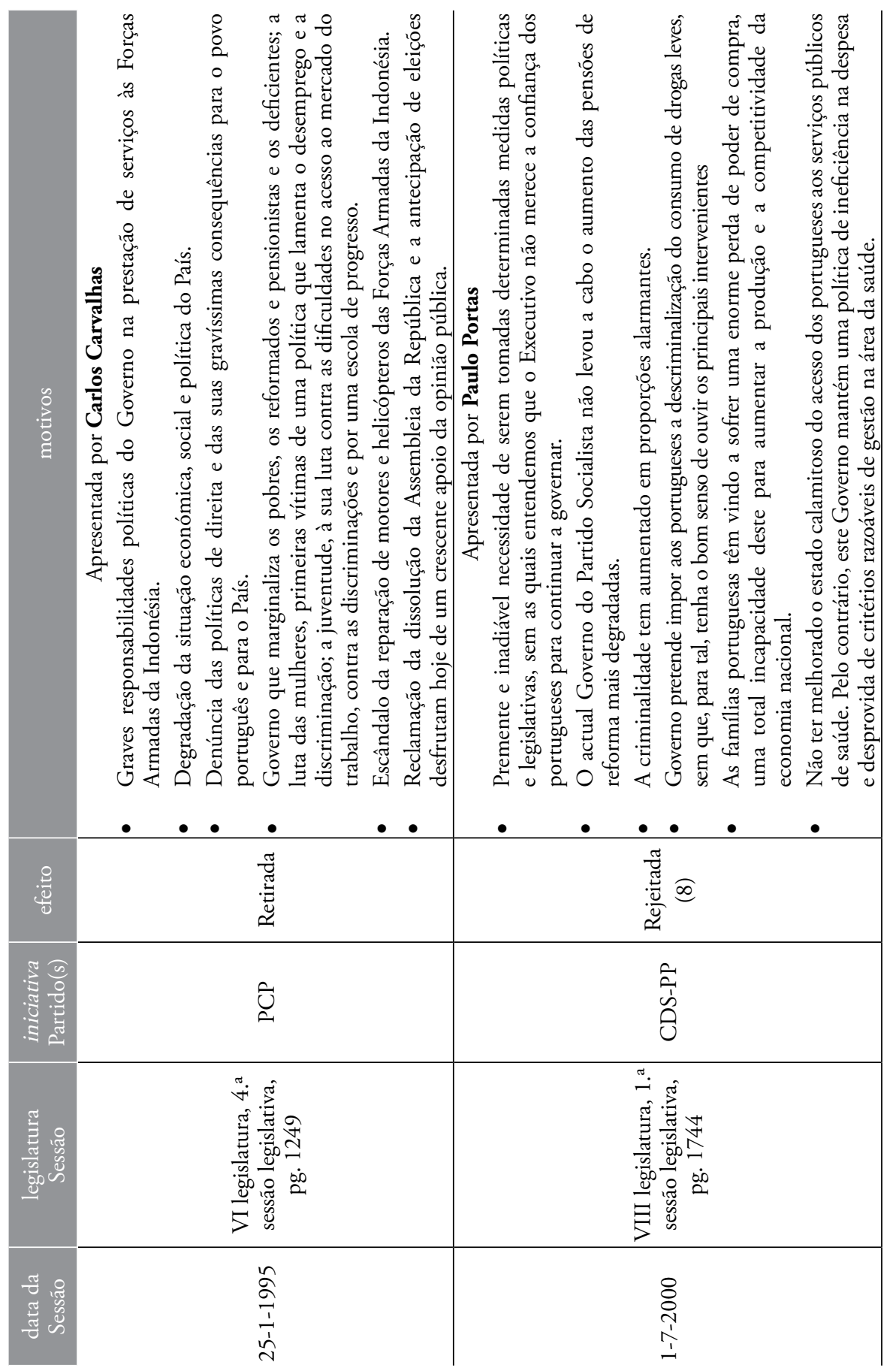




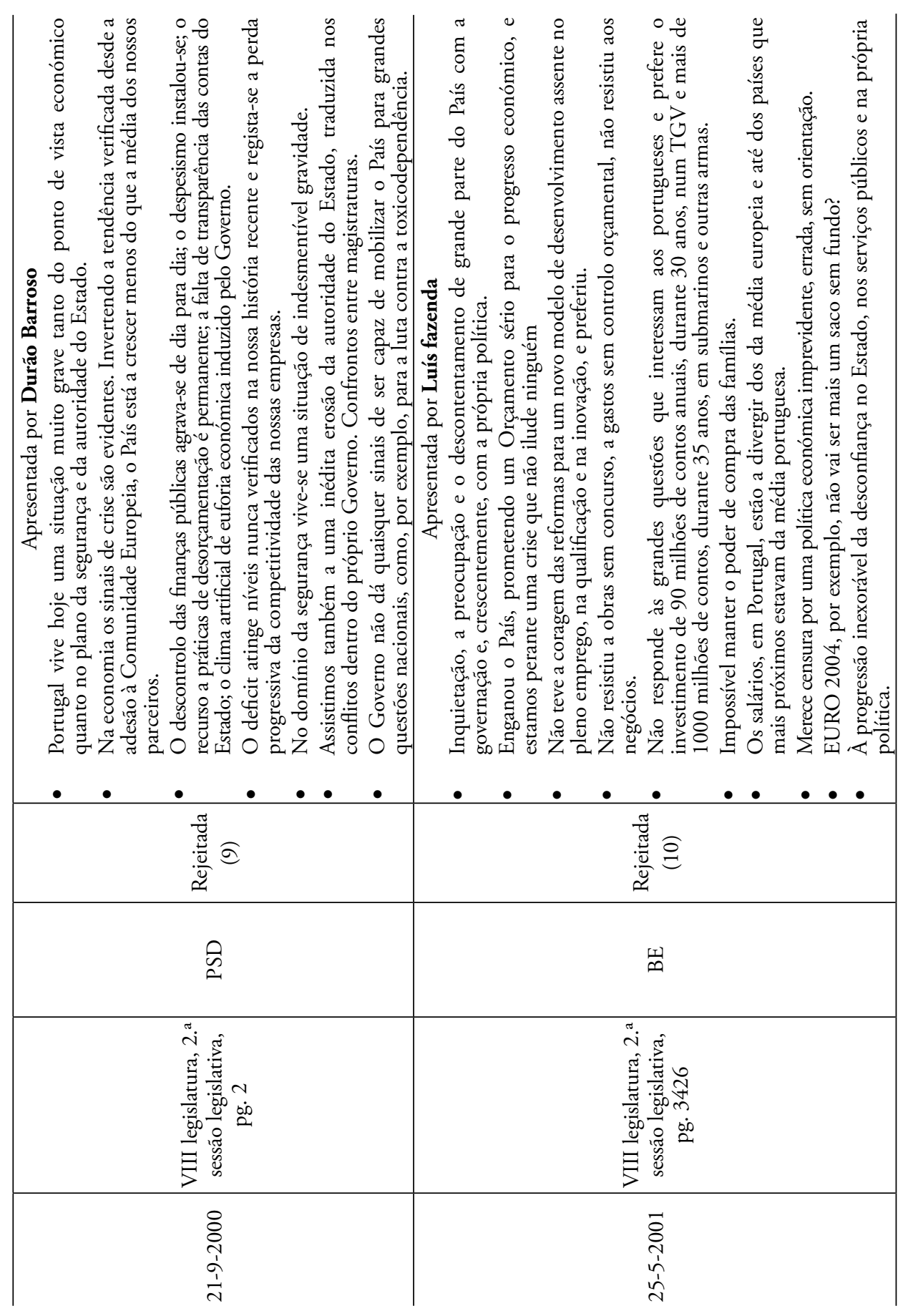




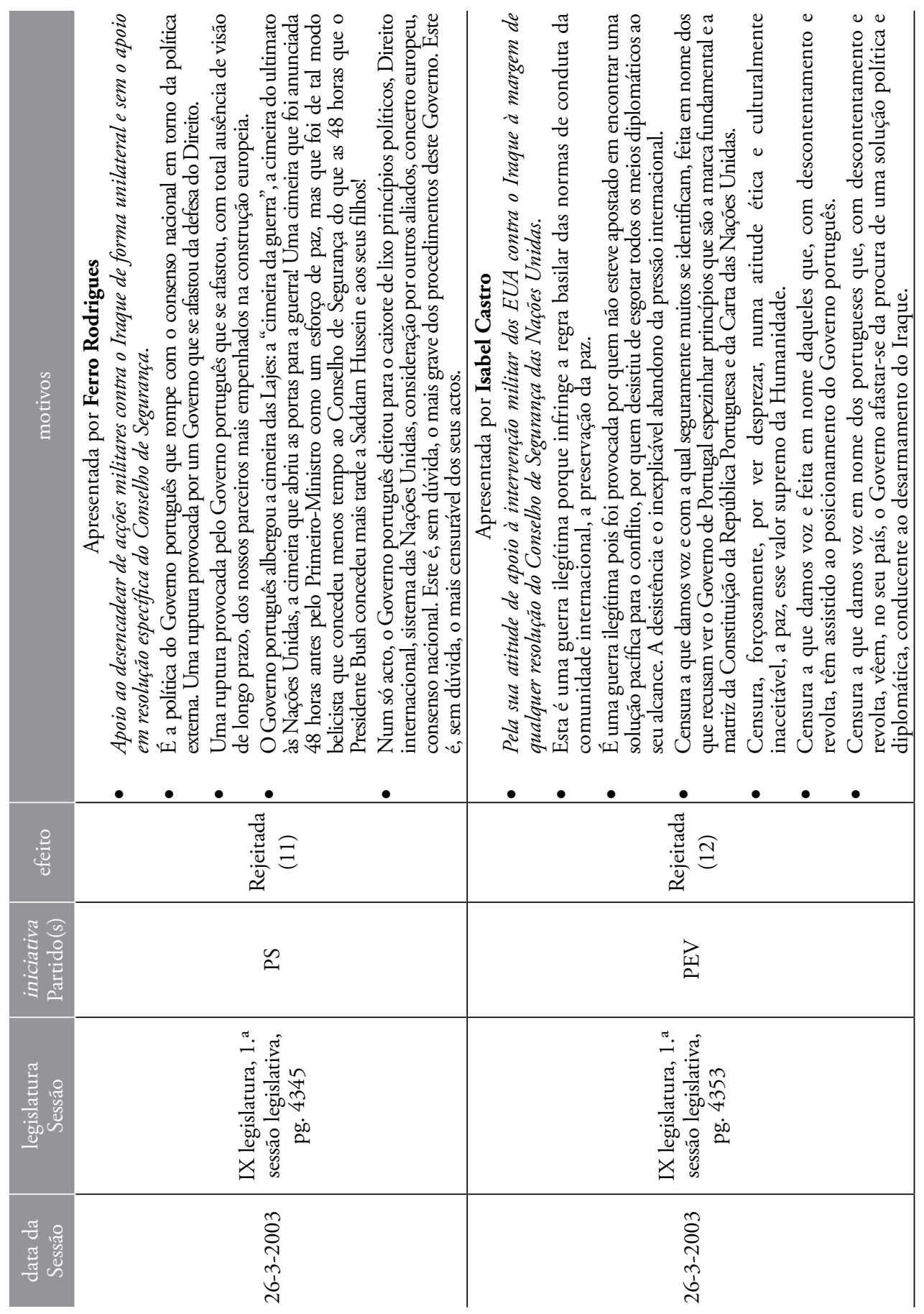




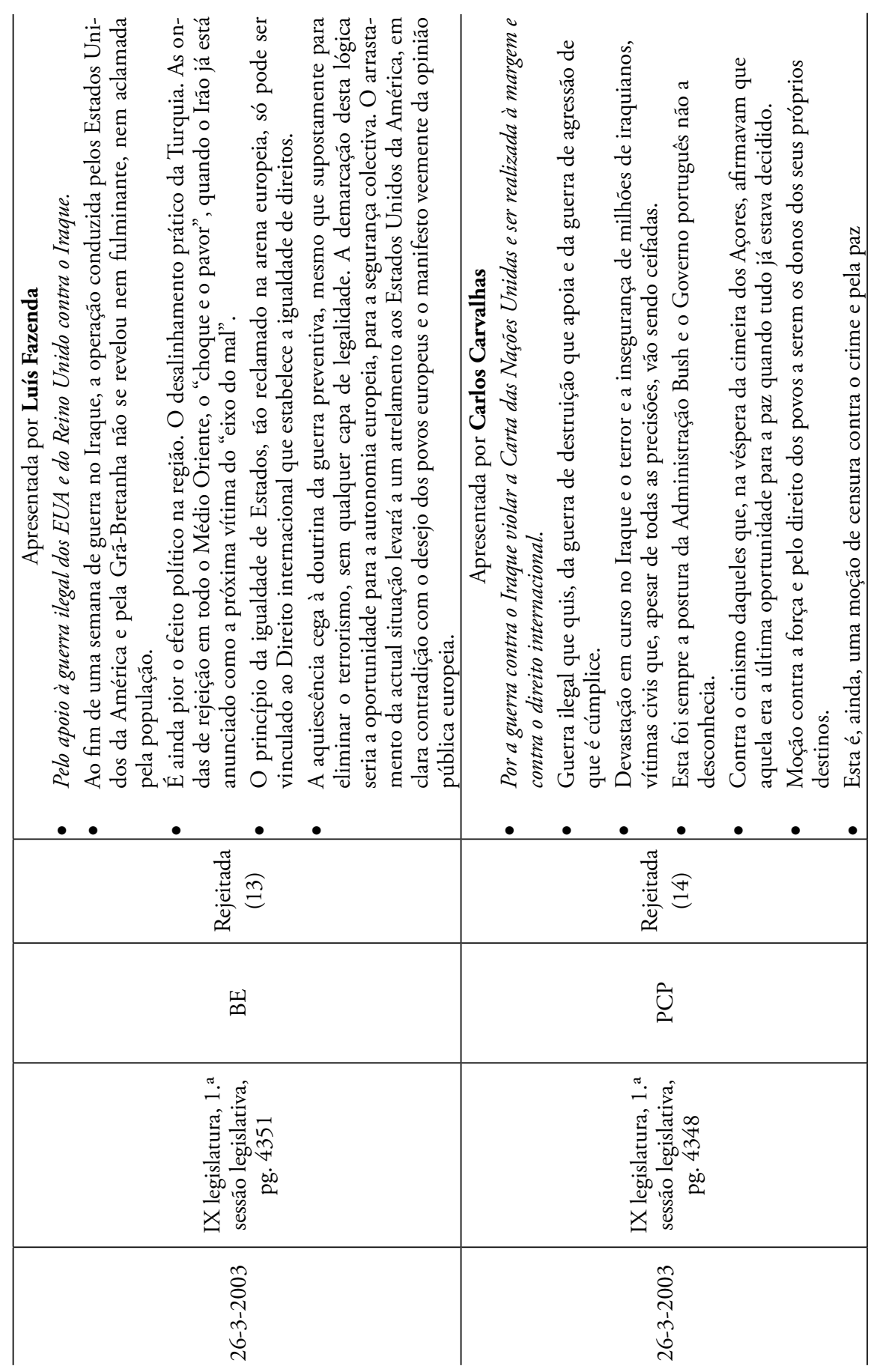




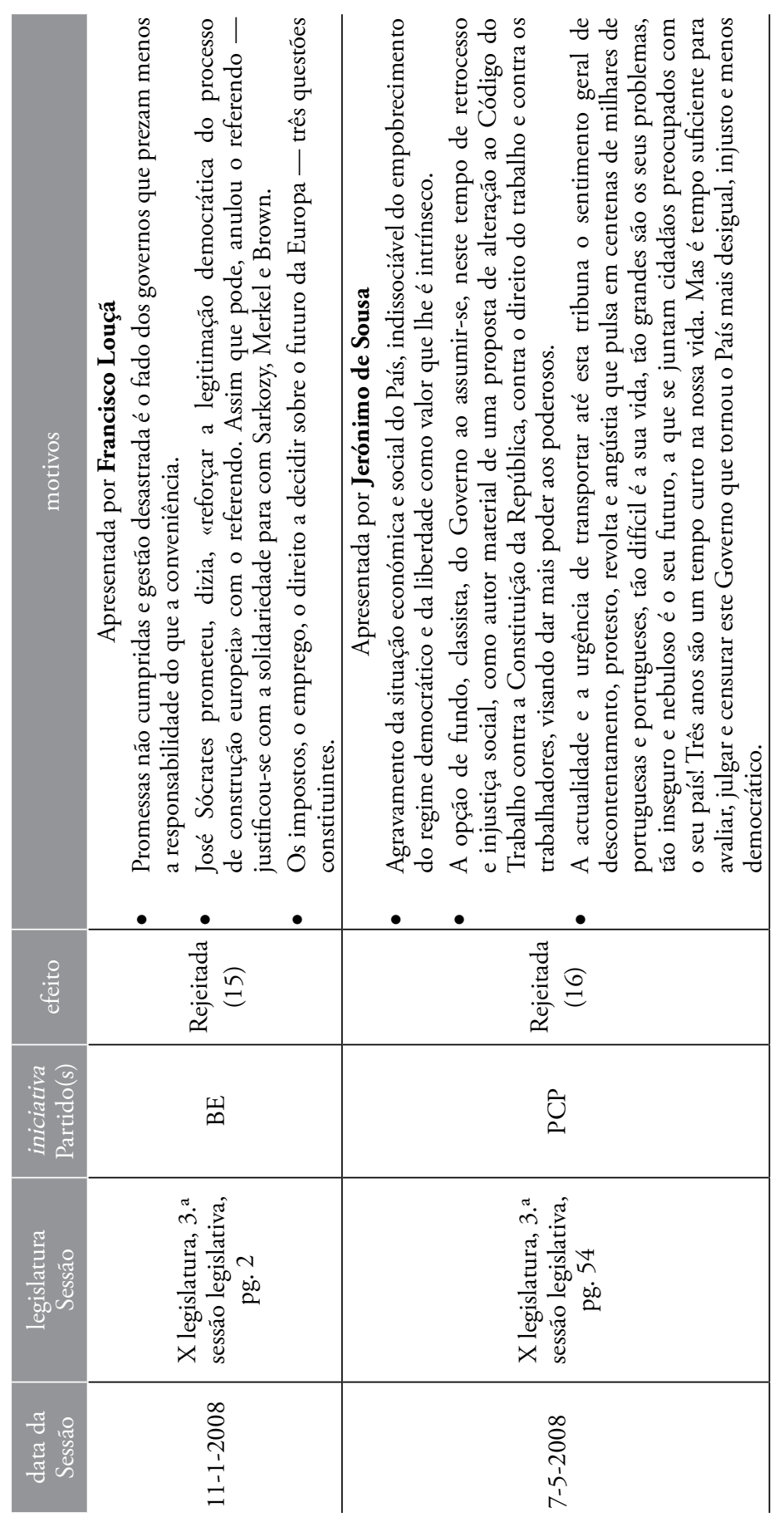




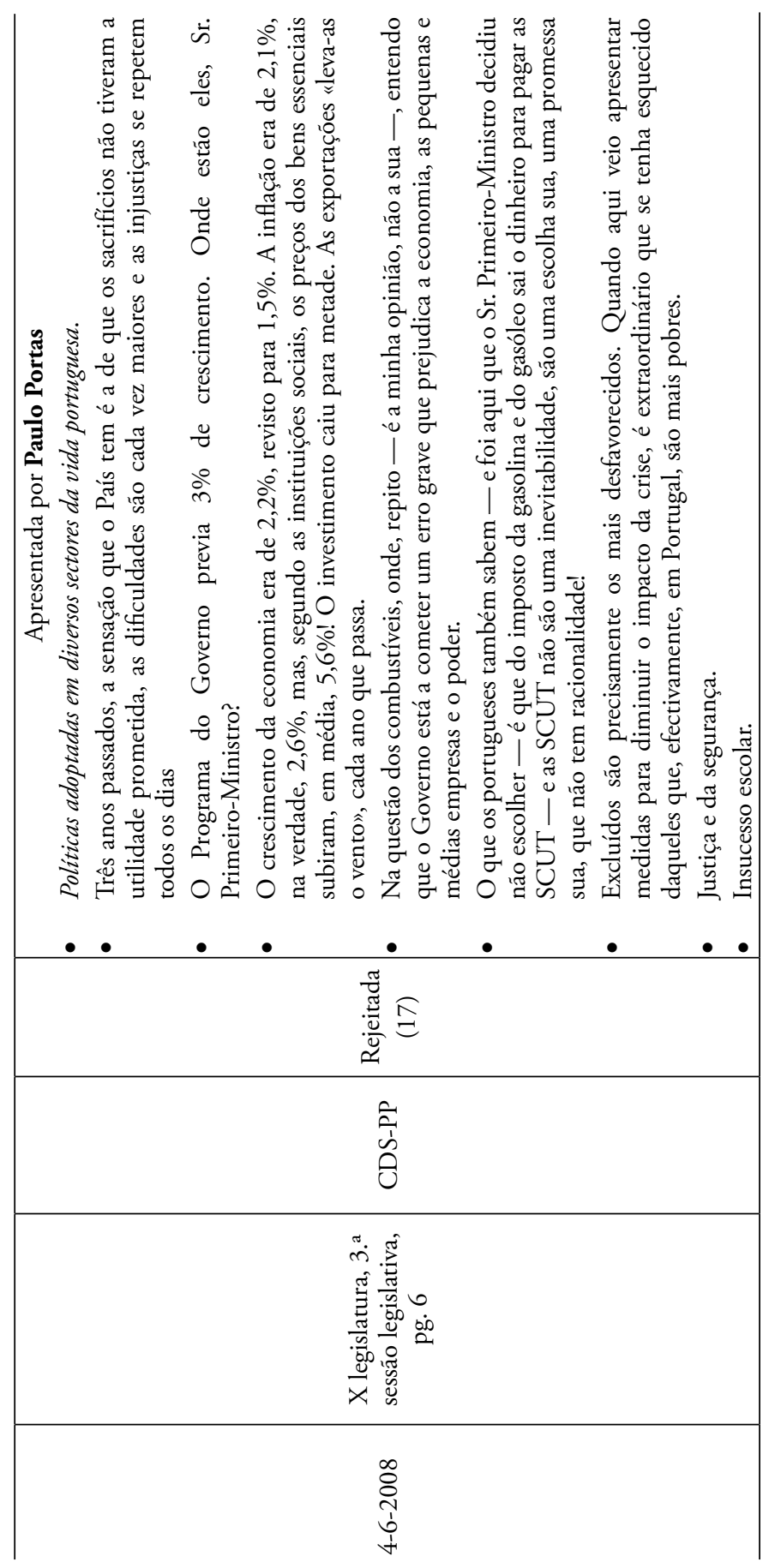




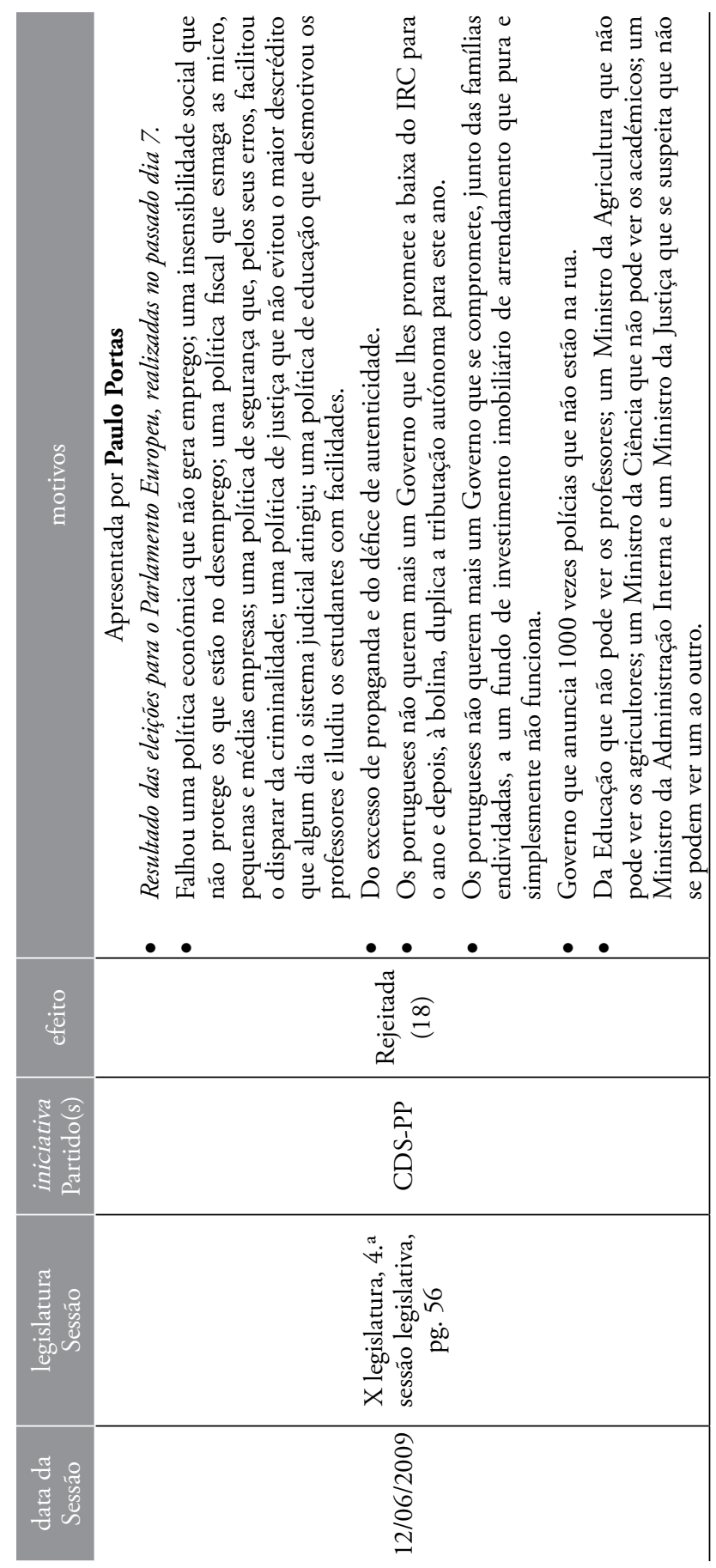




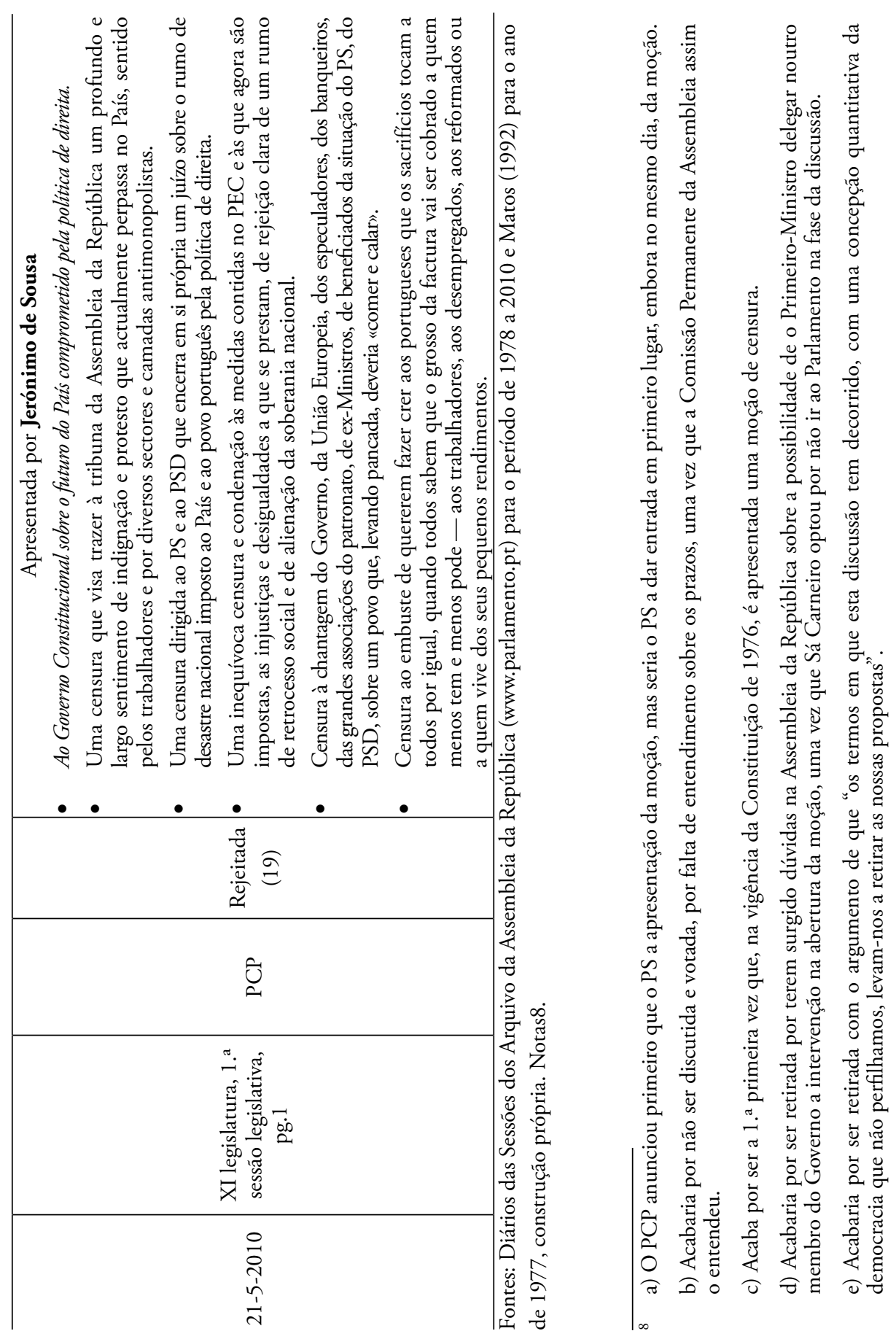


(1) e (2) PS e PCP apresentam moçôes de censura; o PCP anuncia que votará a moção do PS. Em 7-6-79 o Presidente Eanes dá a demissão ao primeiro-ministro, que só aceitaria continuar se houvesse dissolução. Sete meses e meio (Matos, 1992). As moçôes de censura não foram discutidas porque o Governo se demitiu.

(3) Votada em 4 de Março de 1982 sem que conste a pormenorização em diário do resultado por parido, embora conste que foi rejeitada. Noutra página do diário (p. 2600) pode ver-se que o resultado apurado foi: Votantes - 246: A favor: 116: Adalberto Cabais Ribeiro - círculo de Lisboa - PCP. Adelino Teixeira de Carvalho - círculo do Porto - PS.

(4) Submetida a votação, foi rejeitada, com votos contra do PS, do PSD e da ASDI, votos a favor do PCP, do CDS e do deputado independente António Gonzalez, e as abstençóes do $\mathrm{MDP} / \mathrm{CDE}$ e da UEDS.

(5) Submetida a votação, foi aprovada, com 134 votos a favor, do PS, do PRD, do PCP do MDP/CDE e da deputada independente Maria Santos, 108 votos contra, do PSD, do CDS e do deputado independente Oliveira e Costa, e uma abstenção, do deputado independente Ribeiro Telles.

(6) Submetida à votaçáo, foi rejeitada, com votos contra do PSD e votos a favor do PS, do PCP, do PRD, do CDS, de Os Verdes e dos deputados independentes Helena Roseta, Pegado Liz e Raul Castro.

(7) Foi rejeitada, com votos contra do PSD e votos a favor do PS, do PCP, do CDS-PP, de Os Verdes e dos Deputados independentes João Corregedor da Fonseca e Luís Fazenda.

(8) Submetida a votação, foi rejeitada, com votos contra do PS e do BE, votos a favor do PSD e do CDS-PP e abstençóes do PCP e de Os Verdes

(9) Submetida à votação, foi rejeitada, com votos contra do PS e do BE, votos a favor do PSD e do CDS-PP e abstençóes do PCP e de Os Verdes.

(10) Submetida à votaçáo, foi rejeitada, com votos contra do PS, votos a favor do PCP, de Os Verdes e do BE e abstençóes do PSD e do CDS-PP.

(11) Submetida à votaçáo, não obteve a maioria absoluta dos Deputados em efectividade de funçóes necessária, tendo-se registado 116 votos contra (PSD e CDS-PP) e 109 votos a favor (PS, PCP, BE e Os Verdes).

(12) Submetida à votação, não obteve a maioria absoluta dos Deputados em efectividade de funçôes necessária, tendo-se registado 118 votos contra (PSD, CDS-PP e Deputados do PS) e 105 votos a favor (PS, PCP, BE e Os Verdes).

(13) Submetida à votação, não obteve a maioria absoluta dos Deputados em efectividade de funçóes necessária, tendo-se registado 118 votos contra (PSD, CDS-PP e Deputados do PS) e 107 votos a favor (PS, PCP, BE e Os Verdes).

(14) Submetida à votação, não obteve a maioria absoluta dos Deputados em efectividade de funçôes necessária, tendo-se registado 117 votos contra (PSD, CDS-PP e Deputados do PS) e 107 votos a favor (PS, PCP, BE e Os Verdes).

(15) Submetida à votaçáo, foi rejeitada, com 114 votos contra (do PS), 23 votos a favor (do PCP, do BE, de Os Verdes e da Deputada não inscrita Luísa Mesquita) e 80 abstençóes (do PSD e do CDS-PP).

(17) Submetida à votação, não obteve a maioria absoluta dos Deputados em efectividade de funções, tendo-se registado 119 votos contra (PS), 12 votos a favor (CDS-PP) e 93 abstençóes (PSD, PCP, BE, Os Verdes e 1 Deputada náo inscrita 


\section{Grafico n. ${ }^{02}$ : tipo de moçáo/ Autorn/n..$^{\circ}$ vezes em que foi usado o instituto de controlo - 1977-2010}

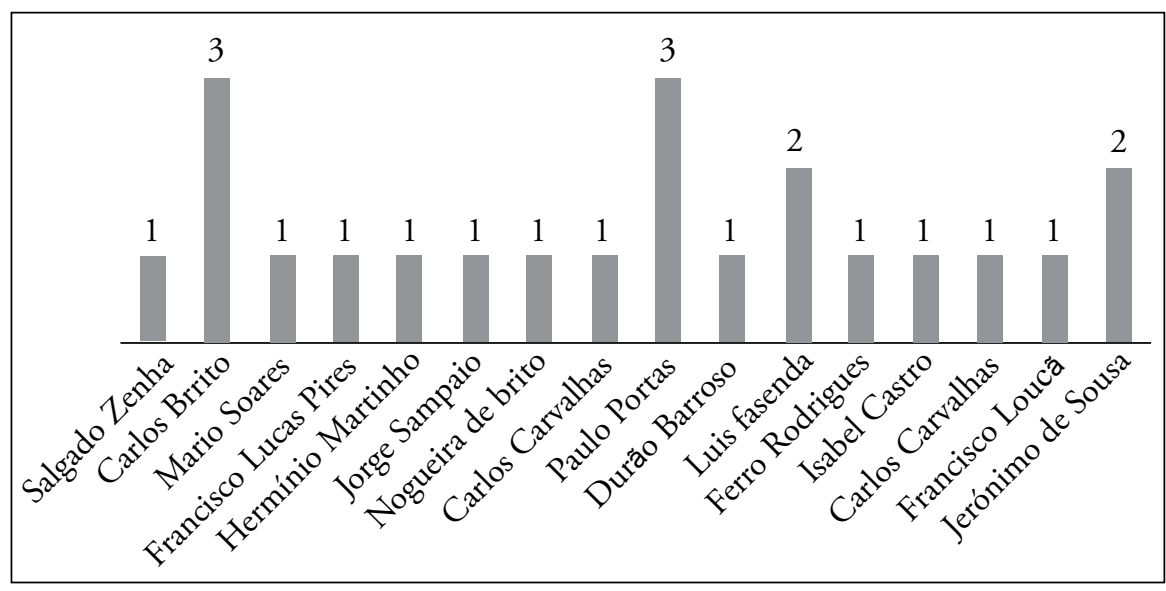

A análise aos objectivos e motivaçôes das várias moçôes de censura no período de 1977-2010 permitem concluir que a prática parlamentar tem demonstrado que a censura é um meio ou canal adequado para análise das crises de governo. A mesma análise não permite concluir, contudo, que o mesmo instituto de censura admita que a oposição se converta numa parte interessada na própria legislatura (Gaspar, 1990), sendo que se reveste mais num momento ou oportunidade para os partidos parlamentares se poderem debruçar sobre os problemas da (in) estabilidade do regime (1990), podendo, em última análise, tornar-se num mecanismo de ineficácia no panorama constitucional do controlo parlamentar (Montero, 1979).

(18) Submetida à votação, não obteve a maioria absoluta dos Deputados em efectividade de funçôes, tendo-se registado 120 votos contra (PS), 78 votos a favor (66 do PSD, 11 do CDSPP e de 1 Deputado não inscrito) e 22 abstençóes (11 do PCP, 8 do BE, 2 de Os Verdes e de 1 Deputada não inscrita).

(19) Submetida à votação, não obteve a maioria absoluta dos Deputados em efectividade de funçôes, tendo-se registado 92 votos contra (PS), 31 votos a favor (16 do BE, 13 do PCP e 2 de Os Verdes) e 90 abstençóes (69 do PSD e 21 do CDS-PP). 


\section{Conclusão}

Os discursos directos na fase de apresentação (normalmente entre o líder parlamentar de cada partido e o primeiro-ministro9) e debate das várias moçóes de censura, em todas a suas tipologias, permite concluir que não existem, em substância, diferenças nos argumentos apresentados. Dito de outro modo, o discurso do debate, salvo momentos muito concretos que motivam a moção de censura (como a Guerra do Iraque) discorrem num alinhamento que não faz distinguir uma moção de censura ao Governo de uma moção de rejeição do progrma do Governo ou, até, se quisermos dos argumentos duma moção de confiança ao Governo, na fase de debate da oposição.

À margem da importância do instituto da moção de censura enquanto mecanismo de controlo político do Governo, o sujeito da censura, é sempre censurado da mesma e pela forma e conteúdo verificado noutros mecanismo de controlo parlamentar da actuação do governo, como as interpelaçôes, perguntas ao governo, debates de urgência, comissóes de inquérito, requerimentos, agendamentos potestativos, etc. A ideia, ou facto, defendido em 2000 por António Vitorino, quando referia que o Parlamento não soube agilizar as suas competências e que sobrevive à custa de momentos rituais, mantém-se e, até, se alarga ao instituto do controlo político do Governo, mesmo passadas 4 legislaturas e 5 Governos após aquela observação e, 11 legislaturas e 18 Governos no período em análise.

\section{RefERÊNCIAS Bibliográficas}

Asensio, Rafael Jiménez (2001) “¿Una Nueva Noción de Responsabilidad Política en el Sistema Constitucional Español?”. Recensión del libro de Rafael Bustos: La responsabilidad política del Gobierno: ¿̨realidad o ficción?’, Colex, Madrid.

Bergman, Torbjorn (1993). "Formation rules and minority governments". European Journal of Political Research Vol. 23: 55-66.

9 Veja-se, por exemplo, a polémica causada por Sá Carneiro quando não compareceu ao debate da moção de censura de iniciativa do PCP, em 19 de Março de 1982, tendo delegado no seu Vice-primeiro-ministro Freitas do Amaral. 
Bonnemaison, María A. (2000). "Mecanismos Constitucionais de Control del Poder Público". Centro de Estudios Políticos y Administrativos de La Facultad de Derecho de La Universidad de Carabobo.

Canotilho, J.J. Gomes (2003). "Direito Constitucional e Teoria da Constituição", Portugal: Almedina.

Cheilub, José António e Limongi, Fernando (2002). “Democratic Institutions na Regime Survival; Parlamentary and Presidential Democracies Reconsidered". Annual Review of Political Science, Vol. 5, pp. 151-79.

Encicloédia Britânica (2010). “Vote of confidence”. Encyclopædia Britannica Online. 13 Jul. 2010. <http://www.britannica.com/ebchecked/topic/633033/vote-of-confidence>.

Virgala, Eduardo (1987). "La Responsabilidad Política del Gobierno en la República Federal de Alemania: la Moción de censura constructiva y las Mociones de Reprobación”. Revista Española de Derecho Constitucional, Año 7. Núm. 21. Septiembre-Diciembre 1987.

Gaspar, Carlos (1990). "O processo constitucional e a estabilidade do regime”. Análise Social. Vol. XXV, N¹05-106, pp. 9-29.

Heard, A. (2007). "Just what is a Vote of Confidence? The Curious Case of May 10, 2005". Canadian Journal of Political Science. Vol. 40 N², pp. 395-416.

Heard, Andrew (2007). "Just what is a Vote of Confidence? The Curious Case of May 10, 2005". Canadian Journal of Political Science. Vol. 40, №2, pp. 395- 416

Kelly, Richard e Powell, Thomas (2010). Confidence Motions. Reino Unido: Parliament and Constitution Centre. House of Commons Library..

Lei Constitucional No 1 de 12 de agosto de 2005.

Leston-Bandeira, Cristina (2000). "A Assembleia da República de 1976 a 1999: da legislação à legitimação”. Análise Social. Vol. XXXV N¹54-155, pp. 175-205.

Lobato, Anderson Orestes Cavalcante (2001). "Política, Constituiçấo e Justiça: Os desafios para a Consolidação das Instituições Democráticas”. Revista de Sociologia e Política, No17, pp. 45-52.

Marques, Maria Aldina (2008). Quando a cortesia é agressiva. Expressäo de cortesia e imagem do outro. $O$ fascinio da linguagem. Homenagem a Fernanda Irene Fonseca. Http://ler.letras.up.pt/ uploads/ficheiros/6710.pdf.

Maskell, Jack (2007). No Confidence. Votes and Other Forms of Congressional. Censure of Public Officials. Congressional Research Service, Report RL34037, American Law Division, Richard S. Beth Government and Finance Division. 
Matos, Luís Salgado de (1992). "O sistema político português e a Comunidade Europeia”. Análise Social. Vol. XXVII (118-119) N4-5, pp.773-787.

Mónica, Maria Filomena (1996). "As reformas eleitorais no constitucionalismo monárquico, 18521910”. Análise Social. Vol. XXXI (139), N5, pp. 1039-1084.

Montero, José R. (1979). "La Moción de Censura en la Constitución de 1978: Supuestos Constituyentes e Consequencias Políticas”. Revista de Estudios Politicos, N¹2, pp. 5-40.

Nohlen, Dieter (1991). "Presidencialismo vs. Parlamentarismo en America Latina. Notas sobre el debate actual desde una perspectiva comparada". Revista de Estudios Políticos (Nueva Época), $N^{\circ} 74 . p p .43-54$

Pennings, Paul (2000). "Parliamentary Control of the Executive in 47 Democracies". 28th Joint Sessions of Worksops of the European Consortium for Political Research.

Portero, José Antonio (1998). "El control parlamentario del gobierno". Working Paper Nº142, Universidad de La Coruña.

Powell, Thomas (2004). Confidence Motions. Parliament and Constitution Centre. Standard Note: SN/PC/2873. House of Commons.

Rebelo de Sousa, Marcelo e Melo, Alexandrino José (2000). Constituiçāo da República Portuguesa. Comentada. Lisboa: Lex Editora..

Saalfeld, Thomas (2000). "Members of parliament and governments in Western Europe: Agency relations and problems oversight". European Journal of Political Research. Vol. 37, №3, pp.353-376.

Salgado, Rafael Arias (1998). "Sistema de partidos". Revista Cuenta y Razón. №35 pp. 73-86.

Santaolalla López, F. (1990). “Derecho Parlamentario Español”. Madrid: Espalsa Calpe.

Santos, Fabiano (2000). "Institutional Choices and transition by transition: Political Systems in Brasil and Spain from a compararive perspective”. Dados, Revista de Ciencias Sociais. Vol. 43, No 4.

Segado, Francisco Fernández (1987). "La Cuestión de Confianza: Marco Juridico-Constitucional y Praxis Política”. Revista Española de Derecho Constitucional. Año 7. № 21, pp. 37-98

Vitorino, António e Fernandes, Mário João de Brito (2000). "A representação da crise da política em Portugal”. Análise Social. Vol. XXXIV (154-155), pp. 259-313.

Zovatto, Daniel e Orozco, Jesús (2007). Reforma Politica y Electoral en América latina 1978-2007: Lectura regional comparada. International Institute for Democracy and Electoral Assistance. 


\section{Tabela 4: composição dos vários Governos Constitucionais}

\begin{tabular}{|c|c|}
\hline Gov & Notas \\
\hline $\begin{array}{l}\text { I Governo Constitucional - 1976- } \\
1978 \text { (Mário Soares) }\end{array}$ & $\begin{array}{l}\text { O I Governo Constitucional tomou posse a } 23 \text { de Julho de } \\
\text { 1976, sendo constituído pelo Partido Socialista com base nos } \\
\text { resultados das eleiçóes de } 25 \text { de Abril de } 1976 \text {. Terminou o } \\
\text { seu mandato a } 23 \text { de Janeiro de } 1978 \text {. }\end{array}$ \\
\hline $\begin{array}{l}\text { II Governo Constitucional - } 1978 \\
\text { (Mário Soares) }\end{array}$ & $\begin{array}{l}\text { O II Governo Constitucional tomou posse a } 23 \text { de Janeiro de } \\
\text { 1978, sendo constituído por uma coligaçáo entre o Partido } \\
\text { Socialista e o Centro Democrático Social. Terminou o seu } \\
\text { mandato a } 29 \text { de Agosto de } 1978 \text {. } \\
\end{array}$ \\
\hline $\begin{array}{l}\text { III Governo Constitucional - } 1978 \\
\text { (Nobre da Costa) }\end{array}$ & $\begin{array}{l}\text { O III Governo Constitucional tomou posse a } 29 \text { de } \\
\text { Agosto de } 1978 \text {, sendo constituído por iniciativa do } \\
\text { Presidente da República. Terminou o seu mandato a } 22 \\
\text { de Novembro de } 1978 \text {. }\end{array}$ \\
\hline $\begin{array}{l}\text { IV Governo Constitucional - 1978- } \\
1979 \text { (Mota Pinto) }\end{array}$ & $\begin{array}{l}\text { O IV Governo Constitucional tomou posse a } 22 \text { de } \\
\text { Novembro de } 1978 \text {, tendo constituído por iniciativa do } \\
\text { Presidente da República. Terminou o seu mandato a } 7 \text { de } \\
\text { Julho de } 1979 \text {. }\end{array}$ \\
\hline $\begin{array}{l}\text { V Governo Constitucional - 1979-1980 } \\
\text { (Lurdes Pintassilgo) }\end{array}$ & $\begin{array}{l}\text { O V Governo Constitucional tomou posse a } 7 \text { de Julho } \\
\text { de 1979, sendo constituído por iniciativa do Presidente da } \\
\text { República. Terminou o seu mandato a } 3 \text { de Janeiro de } 1980 .\end{array}$ \\
\hline $\begin{array}{l}\text { VI Governo Constitucional - 1980- } \\
1981 \text { (Sá Carneiro) }\end{array}$ & $\begin{array}{l}\text { O VI Governo Constitucional tomou posse a } 3 \text { de Janeiro } \\
\text { de } 1980 \text {, sendo constituído pela coligaçáo eleitoral formada } \\
\text { pelo Partido Social-Democrata, o Centro Democrático Social } \\
\text { e o Partido Popular Monárquico, com base nos resultados } \\
\text { das eleiçóes de } 2 \text { de Dezembro de } 1979 \text {. Terminou o seu } \\
\text { mandato a } 9 \text { de Janeiro de } 1981 \text {, na sequência do falecimento } \\
\text { do Primeiro-Ministro, em } 4 \text { de Dezembro de } 1980 \text {. } \\
\end{array}$ \\
\hline $\begin{array}{l}\text { VII Governo Constitucional - } 1981 \\
\text { (Pinto Balsemão) }\end{array}$ & $\begin{array}{l}\text { O VII Governo Constitucional tomou posse a } 9 \text { de Janeiro } \\
\text { de } 1981 \text {, sendo constituído pela coligaçáo formada pelo } \\
\text { Partido Social-Democrata, o Centro Democrático Social e o } \\
\text { Partido Popular Monárquico. Terminou o seu mandato a } 4 \text { de } \\
\text { Setembro de } 1981 \text {. }\end{array}$ \\
\hline $\begin{array}{l}\text { VIII Governo Constitucional - 1981- } \\
1983 \text { (Pinto Balsemão) }\end{array}$ & $\begin{array}{l}\text { O VIII Governo Constitucional tomou posse a } 4 \text { de } \\
\text { Setembro de 1981, sendo constituído pela coligaçáo formada } \\
\text { pelo Partido Social-Democrata, o Centro Democrático Social } \\
\text { e o Partido Popular Monárquico. Terminou o seu mandato a } \\
9 \text { de Junho de 1983. }\end{array}$ \\
\hline $\begin{array}{l}\text { IX Governo Constitucional - 1983- } \\
1985 \text { (Mário Soares) }\end{array}$ & $\begin{array}{l}\text { O IX Governo Constitucional tomou posse a } 9 \text { de Junho de } \\
\text { 1983, sendo constituído por uma coligação pós-eleitoral entre } \\
\text { o Partido Socialista e o Partido Social-Democrata, com base } \\
\text { nos resultados das eleiçóes de } 25 \text { de Abril de } 1983 \text {. Terminou } \\
\text { o seu mandato a } 6 \text { de Novembro de } 1985 \text {. }\end{array}$ \\
\hline
\end{tabular}




\begin{tabular}{|c|c|}
\hline Governo & Notas \\
\hline $\begin{array}{l}\text { X Governo Constitucional - 1985- } \\
1987 \text { (Cavaco Silva) }\end{array}$ & $\begin{array}{l}\text { O X Governo Constitucional tomou posse a } 6 \text { de Novembro } \\
\text { de } 1985 \text {, sendo constituído pelo Partido Social-Democrata, } \\
\text { com base nos resultados das eleiçóes de } 6 \text { de Outubro de } \\
1985 \text {. Terminou o seu mandato a } 17 \text { de Agosto de } 1987 \text {. }\end{array}$ \\
\hline $\begin{array}{l}\text { XI Governo Constitucional - 1987- } \\
1991 \text { (Cavaco Silva) }\end{array}$ & $\begin{array}{l}\text { O XI Governo Constitucional tomou posse a } 17 \text { de Agosto } \\
\text { de } 1987 \text {, sendo constituído pelo Partido Social-Democrata, } \\
\text { com base nos resultados das eleiçóes de } 18 \text { de Julho de } 1987 . \\
\text { Terminou o seu mandato a } 31 \text { de Outubro de } 199 .\end{array}$ \\
\hline $\begin{array}{l}\text { XII Governo Constitucional - 1991- } \\
1995 \text { (Cavaco Silva) }\end{array}$ & $\begin{array}{l}\text { O XII Governo Constitucional tomou posse a } 31 \text { de Outubro } \\
\text { de } 1991 \text {, sendo constituído pelo Partido Social-Democrata, } \\
\text { com base nos resultados das eleiçóes de } 6 \text { de Outubro de } \\
\text { 1991. Terminou o seu mandato a } 28 \text { de Outubro de } 1995 \text {. }\end{array}$ \\
\hline $\begin{array}{l}\text { XIII Governo Constitucional - 1995- } \\
1999 \text { (António Guterres) }\end{array}$ & $\begin{array}{l}\text { O XIII Governo Constitucional tomou posse a } 28 \text { de } \\
\text { Outubro de } 1995 \text {, sendo constituído pelo Partido Socialista } \\
\text { com base nos resultados das eleiçóes de } 1 \text { de Outubro de } \\
\text { 1995. Terminou o seu mandato em } 25 \text { de Outubro de } 1999 .\end{array}$ \\
\hline $\begin{array}{l}\text { XIV Governo Constitucional - 1999- } \\
2002 \text { (António Guterres) }\end{array}$ & $\begin{array}{l}\text { O XIV Governo Constitucional tomou posse a } 25 \text { de } \\
\text { Outubro de } 1999 \text {, sendo constituído pelo Partido Socialista } \\
\text { com base nos resultados das eleiçóes de } 10 \text { de Outubro de } \\
\text { 1999. Terminou o seu mandato a } 6 \text { de Abril de 2002, devido } \\
\text { a demissáo do Primeiro-Ministro. }\end{array}$ \\
\hline $\begin{array}{l}\text { XV Governo Constitucional - 2002- } \\
2004 \text { (Durão Barroso) }\end{array}$ & $\begin{array}{l}\text { O XV Governo Constitucional tomou posse a } 6 \text { de Abril } \\
\text { de } 2002 \text {, sendo constituído pelo Partido Social-Democrata } \\
\text { e pelo Partido Popular, na sequência das eleiçóes de } 17 \text { de } \\
\text { Março de 2002. Terminou o seu mandato a } 17 \text { de Julho de } \\
\text { 2004, devido a demissão do Primeiro-Ministro. }\end{array}$ \\
\hline $\begin{array}{l}\text { XVI Governo Constitucional - 2004- } \\
2005 \text { (Santana Lopes) }\end{array}$ & $\begin{array}{l}\text { O XVI Governo Constitucional tomou posse a } 17 \text { de Junho } \\
\text { de } 2004 \text {, sendo constituído pelo Partido Social-Democrata } \\
\text { e pelo Partido Popular, na sequência das eleiçôes de } 17 \text { de } \\
\text { Março de 2002. Terminou o seu mandato a } 12 \text { de Julho de } \\
\text { 2005. Presidente da República dissolveu o Parlamento e, por } \\
\text { consequência, convocou novas eleiçóes legislativas. }\end{array}$ \\
\hline $\begin{array}{l}\text { XVII Governo Constitucional - 2005- } \\
2009 \text { (José Sócrates) }\end{array}$ & $\begin{array}{l}\text { O XVII Governo Constitucional tomou posse a } 12 \text { de } \\
\text { Março de 2005, sendo constituído pelo Partido Socialista, na } \\
\text { sequência das eleiçóes legislativas de } 2005 \text {. Terminou o seu } \\
\text { mandato a } 26 \text { de Outubro de } 2009 \text {. } \\
\end{array}$ \\
\hline $\begin{array}{l}\text { XVIII Governo Constitucional - 2009- } \\
\text { (...) (José Sócrates) }\end{array}$ & $\begin{array}{l}\text { O XVIII Governo Constitucional tomou posse a } 26 \text { de } \\
\text { Outubro de 2009, sendo constituído pelo Partido Socialista, } \\
\text { na sequência das eleiçóes legislativas de } 2009 \text {. }\end{array}$ \\
\hline
\end{tabular}

Fonte: http://www.portugal.gov.pt; http://www.parlamento.pt. Construção própria. 


\section{Tabela 5: mecanismos de controlo político do Legislativo sobre o Executivo}

\begin{tabular}{|c|c|c|}
\hline País & $\begin{array}{c}\text { moçáo de } \\
\text { censura }\end{array}$ & Observaçóes/efeitos e consequências a) \\
\hline Alemanha & Sim & $\begin{array}{l}\text { Ministers and other Senators may be censured in the Senate for a } \\
\text { wide range of reasons, such as misleading the Senate, failing to answer } \\
\text { questions on notice or to produce documents within a stipulated time, } \\
\text { maladministration of a department, or failing to declare a personal interest } \\
\text { in a matter. The Senate may also pass motions of censure on ministers } \\
\text { who are members of the House of Representatives./Modalities: Censure } \\
\text { motions are initiated by giving a notice of motion, or following a contingent } \\
\text { notice suspending the Senate standing orders. After the suspension } \\
\text { of the standing orders, another motion is moved to give precedence to } \\
\text { the censure motion on that day until it is determined, and if passed, the } \\
\text { censure motion is then moved. The vote on a motion of censure is decided } \\
\text { by a simple majority./Consequences: Unlike the House of Representatives, } \\
\text { a resolution in the Senate censuring the government or a minister can } \\
\text { have no direct constitutional or legal consequences. It is an expression of } \\
\text { the Senates disapproval of the actions or policies of a particular Senator, } \\
\text { minister, or of the government as a whole. Between } 31.12 .1990 \text { and } \\
31.12 .2000 \text {, there have been sixteen successful censure motions moved } \\
\text { in the Senate. In the same period, four unsuccessful censure motions were } \\
\text { moved. All successful motions censured the government, or a government } \\
\text { minister or former minister, and may be assumed to have originated with } \\
\text { non-governmental Senators. }\end{array}$ \\
\hline Austrália & $\operatorname{sim}$ & $\begin{array}{l}\text { Ministers and other Senators may be censured in the Senate for } \\
\text { wide range of reasons, such as misleading the Senate, failing to answer } \\
\text { questions on notice or to produce documents within a stipulated time, } \\
\text { maladministration of a department, or failing to declare a personal interest } \\
\text { in a matter. The Senate may also pass motions of censure on ministers who } \\
\text { are members of the House of Representative. Censure motions are initiated } \\
\text { by giving a notice of motion, or following a contingent notice suspending } \\
\text { the Senate standing orders. After the suspension of the standing orders, } \\
\text { another motion is moved to give precedence to the censure motion on } \\
\text { that day until it is determined, and if passed, the censure motion is then } \\
\text { moved. The vote on a motion of censure is decided by a simple majority. } \\
\text { Unlike the House of Representatives, a resolution in the Senate censuring } \\
\text { the government or a minister can have no direct constitutional or legal } \\
\text { consequences. It is an expression of the Senates disapproval of the actions } \\
\text { or policies of a particular Senator, minister, or of the government as a } \\
\text { whole. Between } 31.12 .1990 \text { and } 31.12 .2000 \text {, there have been sixteen } \\
\text { successful censure motions moved in the Senate. In the same period, } \\
\text { four unsuccessful censure motions were moved. All successful motions } \\
\text { censured the government, or a government minister or former minister, } \\
\text { and may be assumed to have originated with non-governmental Senators. }\end{array}$ \\
\hline
\end{tabular}




\begin{tabular}{|c|c|c|}
\hline País & $\begin{array}{l}\text { moçáo de } \\
\text { censura }\end{array}$ & Observaçóes/efeitos e consequências a) \\
\hline Áustria & $\operatorname{sim}$ & $\begin{array}{l}\text { A motion of censure can be tabled in case of disapproval of actions taken } \\
\text { by Government or in case of a breach of the Constitution or a law. The } \\
\text { Members of the Government are responsible to the National Council } \\
\text { (Article76.1 of the Constitution). /Modalities: The National Council } \\
\text { passes an explicit vote of no confidence in Government or individual } \\
\text { members thereof./Consequences: Depending on the intention of the } \\
\text { motion of censure, either an individual Member of Government, or the } \\
\text { whole cabinet are dismissed. From } 1991 \text { to } 2001,45 \text { motions of censure } \\
\text { were tabled, all by opposition parties, but none was accepted. }\end{array}$ \\
\hline Bélgica & $\operatorname{sim}$ & $\begin{array}{l}\text { The Constitution does not foresee any special grounds for censure. } \\
\text { Motions may be passed following an inquiry, a declaration or a debate. } \\
\text { There are reasoned motions that contain recommendations to the } \\
\text { Government without giving an expression of confidence in respect of it; } \\
\text { pure and simples motions, which the Assembly moves on from to the } \\
\text { following item on its agenda, and constructive motions of no confidence } \\
\text { whose adoption obligates the Government to resign. /Modalities: Article } \\
96 \text { of the Constitution sets out the system for a constructive vote of no } \\
\text { confidence: the Government offers its resignation to the monarch if the } \\
\text { Chamber of Deputies adopts a motion of no confidence by an absolute } \\
\text { majority of its members, providing the monarch with a nomination for } \\
\text { the successor to the Prime Minister. /Consequences: When a motion } \\
\text { of no confidence adopted by the Chamber of Deputies contains the } \\
\text { proposed successor to the Prime Minister, the federal Government must } \\
\text { resign and the monarch must name the proposed successor as the Prime } \\
\text { Minister. If the Chamber of Deputies adopts a motion of no confidence } \\
\text { without proposing a successor, the monarch may dissolve the Chamber of } \\
\text { Deputies at the same time as the motion of no confidence (Article } 46 \text { of } \\
\text { the Constitution). By default the Prime Minister in office remains in place. } \\
\text { It is likewise customary for the Chamber to adopt a non-constructive } \\
\text { motion of no confidence, obligating a particular minister to resign. }\end{array}$ \\
\hline Brasil & não & Not applicable/Modalities: Not applicable/Consequences: Not applicable \\
\hline Bulgária & & $\begin{array}{l}\text { A motion of no-confidence may be tabled in the case of disapproval by the } \\
\text { National Assembly of an action taken by the Government./Modalities: A } \\
\text { motion of no-confidence in the Council of Ministers must be seconded } \\
\text { by one fifth or more of the members of the National Assembly (Article } \\
89 \text {, paragraph } 1 \text { of the Constitution). To be passed, the motion requires } \\
\text { a majority of more than half of the votes of all National Assembly } \\
\text { members./Consequences: Should the National Assembly pass a vote of no- } \\
\text { confidence in the Prime Minister or the Council of Ministers, the Prime } \\
\text { Minister hands in his Government's resignation (Article 89, paragraph } 2 \\
\text { of the Constitution). Should the National Assembly reject a vote of no- } \\
\text { confidence in the Council of Ministers, no new motion for a vote of no- } \\
\text { confidence on the same grounds may be tabled before six months lapse. } \\
\text { During the } 1991-2001 \text { period } 14 \text { votes of no-confidence were tabled, all } \\
\text { of them by opposition parties, and all were unsuccessful. }\end{array}$ \\
\hline
\end{tabular}




\begin{tabular}{|c|c|c|}
\hline País & $\begin{array}{l}\text { moçáo de } \\
\text { censura }\end{array}$ & Observaçóes/efeitos e consequências a) \\
\hline Canadá & não & $\begin{array}{l}\text { Confidence is a matter of tradition and the circumstances for tabling a } \\
\text { motion of censure are not specified in any statute or standing order of the } \\
\text { House of Commons. What constitutes a question of confidence in the } \\
\text { Government thus varies with the circumstances./Modalities: Motions of } \\
\text { censure do not require a qualified majority. Confidence motions may be } \\
\text { (i) explicitly worded motions which state, in express terms, that the House } \\
\text { has, or has no, confidence in the Government, or (ii) implicit motions } \\
\text { of confidence, i.e. motions traditionally deemed to be questions of } \\
\text { confidence, such as motions for the granting of supply, motions concerning } \\
\text { the budgetary policy of the Government, and motions respecting the } \\
\text { address in reply to the speech from the throne./Consequences: When } \\
\text { a motion of no confidence is adopted by the House of Commons, the } \\
\text { head of the Government resigns along with the entire cabinet. Defeat } \\
\text { thus usually leads to the calling of a general election. Between } 1991 \\
\text { and } 2001 \text {, no motions of censure were tabled. On the following three } \\
\text { occasions, however, the Government declared that a certain vote would } \\
\text { be considered as a matter of confidence. In March 1991, it declared } \\
\text { that it would consider an opposition motion on health care as a matter } \\
\text { of confidence. In September } 1991 \text {, it declared that it would consider } \\
\text { an opposition motion on agriculture as a matter of confidence, and in } \\
\text { April } 1998 \text {, it declared that an opposition motion on the compensation } \\
\text { of victims of hepatitis C would be considered as a matter of confidence. }\end{array}$ \\
\hline Chipre & não & $\begin{array}{l}\text { Circumstances: Not applicable/Modalities: Not applicable/Consequences: } \\
\text { Not applicable }\end{array}$ \\
\hline Croácia & $\operatorname{sim}$ & $\begin{array}{l}\text { A vote of no confidence in the Prime Minister, in individual cabinet } \\
\text { members, or in the government as a whole, can be tabled (Article } 115 \\
\text { of the Constitution)./Modalities: A vote of no confidence may be } \\
\text { requested by at least one fifth of the members of the parliament, as well } \\
\text { as by the Prime Minister. No debate or vote of no confidence may be } \\
\text { taken before seven days have elapsed from the date when the motion was } \\
\text { submitted to the parliament. The debate and vote of no confidence are } \\
\text { carried through not later than } 30 \text { days from the day the motion was put } \\
\text { before the parliament. A no-confidence decision is accepted if it has been } \\
\text { passed by the majority of all parliamentarians./Consequences: If a vote } \\
\text { of no confidence in the Prime Minister or in the government as a whole } \\
\text { is passed, the Prime Minister and his cabinet submit their resignation. If } \\
\text { a vote of no confidence in an individual cabinet member is passed, the } \\
\text { Prime Minister may propose another member to the parliament for a } \\
\text { vote of confidence, or the Prime Minister and the cabinet as a whole may } \\
\text { submit their resignation. If Parliament rejects the proposal for a vote of } \\
\text { no confidence, the representatives who have submitted it may not make } \\
\text { the same proposal again before six months have elapsed. Since } 1990 \text {, } 16 \\
\text { motions of no confidence have been tabled by the opposition. None has } \\
\text { been carried. }\end{array}$ \\
\hline
\end{tabular}




\begin{tabular}{|c|c|c|}
\hline País & $\begin{array}{c}\text { moçáo de } \\
\text { censura }\end{array}$ & Observaçóes/efeitos e consequências a) \\
\hline Dinamarca & $\operatorname{sim}$ & $\begin{array}{l}\text { A motion of censure may be tabled in the case of disapproval of actions } \\
\text { taken by the government, of a breach of the Constitution and/or laws, } \\
\text { as well as in the case of general dissatisfaction with the government./ } \\
\text { Modalities: For a resolution to be passed by the parliament, more } \\
\text { than half the members must be present and take part in the voting. } \\
\text { A resolution is considered passed when the votes cast in favour of a } \\
\text { motion exceed those cast against it (a simple majority)./Consequences: } \\
\text { If a motion of censure is passed, the government resigns or the Prime } \\
\text { Minister issues writs for a general election. Writs for an election may } \\
\text { not be issued after the appointment of a new minister until the Prime } \\
\text { Minister has appeared before Parliament. }\end{array}$ \\
\hline Eslováquia & $\operatorname{sim}$ & $\begin{array}{l}\text { The National Council can pass a vote of no confidence in Government } \\
\text { at any time (Article } 114 \text {, paragraph } 1 \text { of the Constitution). It may also } \\
\text { pass a vote of no confidence in an individual Government member } \\
\text { (Article 116, paragraph } 3 \text { of the Constitution). The proposal to recall } \\
\text { a Government member may also be submitted to the President by the } \\
\text { Prime Minister./Modalities: The motion to pass a vote of no confidence } \\
\text { in Government or a member of it will be discussed by the National } \\
\text { Council if requested by at least one fifth of its deputies (Article } 88 \text {, } \\
\text { paragraph } 1 \text { of the Constitution). The consent of more than } 50 \text { per } \\
\text { cent of all deputies is required to pass a vote of no confidence in } \\
\text { Government or a member of it. /Consequences: If the National } \\
\text { Council passes a vote of no confidence in the Prime Minister or any } \\
\text { other minister, the President will recall him or her. The recalling of } \\
\text { the Prime Minister results in the stepping down of the entire cabinet. } \\
\text { If the President accepts the resignation of a member of Government, } \\
\text { he or she will determine which other member will temporarily } \\
\text { be charged with the management of his or her department. If the } \\
\text { President accepts the Government's resignation, he will entrust it } \\
\text { with the execution of its duties until a new Government is appointed. } \\
\text { Between } 1998 \text { and } 2001 \text {, opposition parties in the National Council } \\
\text { have tabled } 12 \text { motions of censure, but none was successful. }\end{array}$ \\
\hline
\end{tabular}




\begin{tabular}{|c|c|c|}
\hline País & $\begin{array}{c}\text { moçáo de } \\
\text { censura }\end{array}$ & Observaçóes/efeitos e consequências a) \\
\hline Eslovénia & $\operatorname{sim}$ & $\begin{array}{l}\text { The National Assembly may pass a vote of no confidence in the } \\
\text { Government only by electing a new Prime Minister on the proposal } \\
\text { of at least } 10 \text { deputies and by a majority vote of all deputies (Article } \\
116 \text { of the Constitution). An interpellation with respect to the work } \\
\text { of the Government or an individual minister may be initiated in } \\
\text { the National Assembly by at least } 10 \text { deputies (Article } 118 \text { of the } \\
\text { Constitution)./Modalities: A vote of no confidence in the Government } \\
\text { is passed by electing a new Prime Minister on the proposal of at least } \\
10 \text { deputies and by a majority vote of all deputies. No less than } 48 \\
\text { hours must elapse between the lodging of a proposal to elect a new } \\
\text { Prime Minister and the vote itself, unless the National Assembly } \\
\text { decides otherwise by a two-thirds majority of all deputies, or if the } \\
\text { country is at war or in a state of emergency. Where a Prime Minister } \\
\text { has been elected, a vote of no confidence is expressed in him if on } \\
\text { the proposal of at least } 10 \text { deputies (Article } 116 \text { of the Constitution). } \\
\text { An interpellation with respect to the work of Government or an } \\
\text { individual minister may be initiated in the National Assembly by at } \\
\text { least } 10 \text { deputies. If, after the debate following such interpellation, a } \\
\text { majority of all deputies carries a vote of no confidence, the national } \\
\text { Assembly dismisses the Government or the minister (Article } 118 \text { of } \\
\text { the Constitution)./Consequences: Following a successful motion of } \\
\text { censure, the incumbent Prime Minister is dismissed, but together } \\
\text { with his ministers he must continue to perform his regular duties } \\
\text { until the swearing in of a new Government. Ministers cease to hold } \\
\text { office whenever the Prime Minister ceases to do so and whenever such } \\
\text { ministers are dismissed. They must, however, continue to perform } \\
\text { their regular duties until the appointment of new ministers (Article } \\
115 \text { of the Constitution). }\end{array}$ \\
\hline Espanha & $\operatorname{sim}$ & $\begin{array}{l}\text { Congress may call Government to account politically by adopting a } \\
\text { motion of censure by overall majority of its members (Article } 113 \text { of } \\
\text { the Constitution). A motion of censure does not have to be linked to } \\
\text { any specific circumstance./Modalities: The motion of censure must be } \\
\text { proposed by at least one tenth of the members of Congress and must } \\
\text { include a candidate for the office of Presidency of Government. It may not } \\
\text { be voted until five days after it has been submitted. During the first two } \\
\text { days of this period, alternative motions may be submitted. If a motion of } \\
\text { censure is not adopted by Congress, its signatories may not submit another } \\
\text { during the same period of sessions./Consequences: If Congress adopts } \\
\text { a motion of censure, Government submits its resignation to the King, } \\
\text { and the candidate proposed in the motion of censure has the confidence } \\
\text { of Congress. The King appoints him or her President of Government. } \\
\text { Between } 1990 \text { and } 2000 \text {, no motions of censure were tabled. }\end{array}$ \\
\hline
\end{tabular}




\begin{tabular}{|c|c|c|}
\hline País & $\begin{array}{l}\text { moçáo de } \\
\text { censura }\end{array}$ & Observaçóes/efeitos e consequências a) \\
\hline Estónia & $\operatorname{sim}$ & $\begin{array}{l}\text { The parliament may express no confidence in the government, the } \\
\text { Prime Minister, or a minister by a resolution passed by a majority of } \\
\text { parliamentarians (Article } 97 \text { of the Constitution)./Modalities: A no- } \\
\text { confidence motion may be initiated by not less than one fifth of the } \\
\text { members of the parliament by the tabling of a written motion. A no- } \\
\text { confidence motion may not be voted on before the second day after its } \\
\text { tabling, unless the government requires a more expeditious decision. / } \\
\text { Consequences: If no confidence is expressed in the government or the } \\
\text { Prime Minister, the President may, on the proposal of the government and } \\
\text { within three days, call early elections. If a no-confidence vote is adopted } \\
\text { against a minister, the Speaker of the parliament notifies the President, } \\
\text { who dismisses the minister. An expression of no confidence on the same } \\
\text { grounds may be initiated no earlier than three months after the previous } \\
\text { vote of no confidence. Over the past } 10 \text { years, about } 10 \text { motions of no } \\
\text { confidence have been tabled, all of them by the opposition. One motion } \\
\text { of no confidence has been adopted. }\end{array}$ \\
\hline França & $\operatorname{sim}$ & $\begin{array}{l}\text { There are no basic conditions for tabling motions of no confidence; their } \\
\text { authors are free to choose reasons for wishing to censure the Government. } \\
\text { On the other hand, the tabling and carrying of motions of censure is } \\
\text { subject to procedural conditions. /Modalities: Such a motion is not } \\
\text { acceptable unless it is signed by at least a tenth of the members of the } \\
\text { Assembly. The same member may not be the signatory of more than three } \\
\text { motions of censure during a single ordinary session, and of more than } \\
\text { one during a single extraordinary session, except if the motion is tabled in } \\
\text { response to making the passing of a bill an issue of responsibility (Article } \\
49.2 \text { ). Voting may not take place within forty-eight hours of the motion } \\
\text { being introduced. A motion of censure may not be adopted unless a } \\
\text { majority of the members of the Assembly vote for it, with only the votes in } \\
\text { favour of the motion of censure being counted. A Government may not } \\
\text { be overturned from then on except by the express will of the majority of } \\
\text { the deputies, the absentees as well as the deputies wishing to abstain, being } \\
\text { reputed to support the Government. /Consequences: When the National } \\
\text { Assembly adopts a motion of censure, the Prime Minister must hand in } \\
\text { the Government's resignation to the President. A motion of censure has } \\
\text { been adopted under the Fifth Republic once, on } 4 \text { October } 1962 \text {. When } \\
\text { the Prime Minister had submitted the Government's resignation, the } \\
\text { President held him in his post in order to see through the jobs at hand and } \\
\text { announced the dissolution of the National Assembly. When the elections } \\
\text { drew a favourable majority for the President and the overthrown Prime } \\
\text { Minister, the latter was reinstated by the President. From } 1991-2002 \text {, ten } \\
\text { motions of censure were tabled at the initiative of the deputies (five under } \\
\text { the 9th legislature, three under the } 10 \text { th and two under the 6th), and six } \\
\text { motions of censure based on Article } 49 \text {, paragraph } 3 \text { of the Constitution } \\
\text { (three under the 9th and three under the } 10 \text { th). These motions of censure } \\
\text { were all tabled by opposition groups and none of them was adopted. }\end{array}$ \\
\hline
\end{tabular}




\begin{tabular}{|c|c|c|}
\hline País & $\begin{array}{l}\text { moção de } \\
\text { censura }\end{array}$ & Observaçóes/efeitos e consequências a) \\
\hline Grécia & $\operatorname{sim}$ & $\begin{array}{l}\text { The parliament may withdraw its confidence from the Government or } \\
\text { from a member of the Government. A motion of no confidence in the } \\
\text { Government may not be submitted before the lapse of six months from } \\
\text { the rejection by the parliament of such a motion (Article } 84.2 \text { of the } \\
\text { Constitution)./Modalities: The motion of no confidence must be signed } \\
\text { by at least one sixth of the deputies and must contain in detail the topic to } \\
\text { be discussed. By exception, a motion of no confidence may be submitted } \\
\text { before the lapse of six months if it is signed by all deputies. The debate on } \\
\text { the motion of no confidence commences two days after the submission } \\
\text { of the motion, and may not be extended beyond three days from the } \\
\text { commencement thereof. The vote on the motion of no confidence must } \\
\text { be taken immediately after the end of the debate. It may, however, be } \\
\text { postponed for forty-eight hours should the Government request such a } \\
\text { postponement. A motion of no confidence is only upheld if approved } \\
\text { by an absolute majority of the total number of deputies./Consequences: } \\
\text { Should a motion of no confidence be adopted, the Prime Minister resigns } \\
\text { along with his/her cabinet. The President has the discretionary power to } \\
\text { dissolve the parliament and proclaim elections. However, in case a motion } \\
\text { adopted concerns an individual member of the Government, then only } \\
\text { this minister or vice-minister resigns. Over the last years, two motions } \\
\text { of censure against the Government (1993 and 1996), and two motions } \\
\text { against individual ministers (1999 and 2001) have been tabled in the } \\
\text { parliament, but all were rejected. }\end{array}$ \\
\hline Holanda & $\operatorname{sim}$ & $\begin{array}{l}\text { Motions of censure can be tabled in case of disapproval of actions } \\
\text { taken by Government./Modalities: A motion of censure only requires } \\
\text { a simple majority to be passed./Consequences: The consequences of } \\
\text { an adopted motion of censure are the resignation of the cabinet or the } \\
\text { individual member of the cabinet mentioned in the motion. }\end{array}$ \\
\hline Hungria & $\operatorname{sim}$ & $\begin{array}{l}\text { A motion of no confidence in the Prime Minister may be initiated by a } \\
\text { written petition, which includes the nomination for a candidate for the } \\
\text { office of Prime Minister (Article 39A of the Constitution). Such a motion } \\
\text { is considered a motion of no confidence in the government as well./ } \\
\text { Modalities: A motion of no confidence in the Prime Minister is initiated } \\
\text { by no less than one fifth of the members of the parliament. Should, on } \\
\text { the basis of this motion, the majority of parliamentarians withdraw their } \\
\text { confidence, the candidate nominated for Prime Minister is considered } \\
\text { elected. The debate and vote on the motion of no confidence must be } \\
\text { held no earlier than three days and no later than eight days from the date } \\
\text { the motion was tabled./Consequences: Should the parliament fail to give } \\
\text { the government a vote of confidence, the government resigns, and the } \\
\text { candidate nominated for Prime Minister is considered elected. Over the } \\
\text { past } 10 \text { years, The parliament has not tabled any motion of censure. }\end{array}$ \\
\hline
\end{tabular}




\begin{tabular}{|c|c|c|}
\hline País & $\begin{array}{l}\text { moçáo de } \\
\text { censura }\end{array}$ & Observaçóes/efeitos e consequências a) \\
\hline Irlanda & $\operatorname{sim}$ & $\begin{array}{l}\text { A motion of censure may be tabled in case of disapproval of action taken } \\
\text { by the government or in case of governmental failure to obtain approval of } \\
\text { taxation, expenditure or other major policy proposals./Modalities: A motion } \\
\text { of censure needs only a simple majority for adoption./Consequences: On } \\
\text { the adoption of a motion censuring the government, the Prime Minister } \\
\text { may advise the President to dissolve the House of Representatives and cause } \\
\text { a general election, or, if the President declines to do so, steps may be taken } \\
\text { within the House of Representatives to form a new government without a } \\
\text { general election. In any such case, outgoing members of the government } \\
\text { remain in office until their successors are appointed. Individual ministers } \\
\text { may tender their resignation to the President if a motion censuring them } \\
\text { only is adopted or if, due to other circumstances, they choose to resign. The } \\
\text { President accepts such resignations on the advice of the Prime Minister. } \\
\text { From } 1990 \text { to } 2000 \text {, nine motions of confidence were tabled in the House } \\
\text { of Representatives, six originating from the government and three from the } \\
\text { opposition. Overall, four motions were adopted by the chamber. }\end{array}$ \\
\hline Islândia & $\operatorname{sim}$ & $\begin{array}{l}\text { There is no established practice for tabling a motion of no confidence } \\
\text { against the government or an individual minister./Modalities: The } \\
\text { motion of no confidence does not require a qualified majority./ } \\
\text { Consequences: If a motion is adopted, the minister against whom the } \\
\text { motion is directed resigns. If a motion is directed against the Prime } \\
\text { Minister, it is most likely that the whole cabinet would resign. During } \\
\text { the period } 1990 \text { to } 2001 \text {, no motions were tabled. }\end{array}$ \\
\hline Itália & $\operatorname{sim}$ & \\
\hline Japão & $\operatorname{sim}$ & $\begin{array}{l}\text { The adoption of a no-confidence resolution by the House of Councillors } \\
\text { has political effect only./Modalities: For the introduction of a resolution } \\
\text { of censure against the Prime Minister, it is necessary to secure the } \\
\text { support of } 10 \text { or more members. The passage of it requires a majority } \\
\text { of all members who are present./Consequences: The adoption of a no- } \\
\text { confidence resolution does not legally oblige the Prime Minister to } \\
\text { resign. A resolution once rejected by the House is never deliberated again } \\
\text { in the same Diet session. Between } 1995 \text { and } 2004 \text {, six resolutions were } \\
\text { tabled against the Prime Minister, and } 21 \text { against other ministers. All the } \\
\text { resolutions of censure were from opposition parties, and only one was } \\
\text { adopted against a minister. }\end{array}$ \\
\hline Letónia & $\operatorname{sim}$ & $\begin{array}{l}\text { A motion of censure may be tabled by the parliament in the case of the } \\
\text { disapproval of actions taken by the Government, or in case of a breach } \\
\text { of the Constitution or a law./Modalities: A motion of censure requires } \\
\text { a qualified majority./Consequences: If the parliament expresses no } \\
\text { confidence in the Prime Minister, the entire cabinet must resign. } \\
\text { If there is an expression of no confidence in an individual minister } \\
\text { then the minister must resign and another person is invited to replace } \\
\text { him or her by the Prime Minister. Between } 1999 \text { and July, } 2005,18 \\
\text { motions of censure were tabled (once for the entire cabinet, five times } \\
\text { for the Prime Minister and } 12 \text { times for individual ministers). All } 18 \\
\text { motions were unsuccessful ( } 11 \text { were defeated when the parliament } \\
\text { voted, and seven were withdrawn). }\end{array}$ \\
\hline
\end{tabular}




\begin{tabular}{|c|c|c|}
\hline País & $\begin{array}{l}\text { moçáa de } \\
\text { censura }\end{array}$ & Observaçóes/efeitos e consequências a) \\
\hline Lituânia & $\operatorname{sim}$ & $\begin{array}{l}\text { The parliament supervises the activities of the Government, and may } \\
\text { express no confidence in the Prime Minister or a minister (Article } \\
67.9 \text { of the Constitution). Similarly, other officials appointed or } \\
\text { elected by the parliament may be removed from office by a vote of no } \\
\text { confidence./Modalities: During a plenary sitting, at least one-fifth of all } \\
\text { parliamentarians may submit an interpellation motion against the Prime } \\
\text { Minister or a minister. Upon considering the response of the Prime } \\
\text { Minister or minister to the interpellation, the parliament may decide that } \\
\text { the response is not satisfactory, and, by a majority vote of half of all the } \\
\text { members of the parliament, pass a motion of no confidence (Article } 61 \\
\text { of the Constitution). Other officials are removed from office when they } \\
\text { receive a motion of no confidence by a majority vote of all members of } \\
\text { the parliament./Consequences: When more than half of the ministers have } \\
\text { been replaced, the Government must once again be granted its powers by } \\
\text { the parliament or else it must resign. Between } 1990 \text { and } 2005 \text {, there was } \\
\text { one case of a motion of no confidence against the Prime Minister, and } \\
\text { there were two against the Government, and six cases of interpellation } \\
\text { involving no confidence measures against ministers. All motions emanated } \\
\text { from opposition parliamentarians, and in one case of no confidence, the } \\
\text { Prime Minister and Government in corpore had to resign after a motion of } \\
\text { censure was adopted against him (1992). }\end{array}$ \\
\hline Luxembrugo & $\operatorname{sim}$ & $\begin{array}{l}\text { A motion of censure may be tabled at any moment when for one reason } \\
\text { or another the Chamber looses confidence in the Government. There are } \\
\text { no restrictions set out in the constitutional or legislative texts./Modalities: } \\
\text { A simple majority is sufficient for a motion of censure to be accepted./ } \\
\text { Consequences: The consequences of the adoption of a motion of censure } \\
\text { depend upon its content. If it is addressed to the Government as a whole, } \\
\text { everybody in the Government resigns. If it is restricted to one or several } \\
\text { members of the Government, only those implicated are obligated to } \\
\text { resign. There were no motions of censure between } 1990 \text { and } 2000 \text {. }\end{array}$ \\
\hline Noruega & não & \\
\hline Polónia & $\operatorname{sim}$ & $\begin{array}{l}\text { The House may pass a vote of no confidence in the Council of Ministers } \\
\text { as well as in an individual minister (Article } 158 \text { of the Constitution)./ } \\
\text { Modalities: The House passes a vote of no confidence in the Council of } \\
\text { Ministers by a majority of votes of all deputies, on a motion moved by at } \\
\text { least } 46 \text { deputies and which specifies the name of a candidate for Prime } \\
\text { Minister (Article } 158 \text { of the Constitution). A motion to pass a resolution } \\
\text { may be put to a vote no sooner than seven days after it has been submitted. } \\
\text { A subsequent motion of a like kind may be submitted no sooner than } \\
\text { after the end of three months from the day the previous motion was } \\
\text { submitted, unless such a motion is submitted by at least } 115 \text { deputies. } \\
\text { A motion for a vote of no confidence in an individual minister may be } \\
\text { submitted by at least } 69 \text { deputies./Consequences: The President recalls a } \\
\text { minister in whom a vote of no confidence has been passed by a majority } \\
\text { of votes of all deputies. If such a resolution has been passed against the } \\
\text { Council of Ministers, the President accepts its resignation and appoints } \\
\text { a new Prime Minister as chosen by the House, and, on his application, } \\
\text { the other ministers. Over the last } 11 \text { years (1990-2000), } 25 \text { motions } \\
\text { of no confidence have been tabled in the House, most of them against } \\
\text { individual ministers. }\end{array}$ \\
\hline
\end{tabular}




\begin{tabular}{|c|c|c|}
\hline País & $\begin{array}{c}\text { moçáo de } \\
\text { censura }\end{array}$ & Observaçóes/efeitos e consequências a) \\
\hline Portugal & $\operatorname{sim}$ & \\
\hline Reino Unido & $\operatorname{sim}$ & $\begin{array}{l}\text { Members may theoretically table motions of censure or of no confidence } \\
\text { in the Government, or motions critical of individual ministers, at } \\
\text { any time./Modalities: Any member of the House may table a motion } \\
\text { criticising the actions of the Government or of an individual minister. In } \\
\text { most cases these motions are set down for debate on "an early day" (that } \\
\text { is, on no specified date). As the Government itself decides which motions } \\
\text { are to be set down on the order paper for debate in the House, very } \\
\text { few, if any, such motions are formally considered. If, however, a motion } \\
\text { of censure is tabled in the name of the leader of the official opposition, } \\
\text { convention dictates that Government will set it down for debate at an } \\
\text { early opportunity. As with any other motion, a simple majority is all } \\
\text { that is required for a motion of censure to be carried./Consequences: No } \\
\text { resignations immediately ensue as the result of a vote of no confidence } \\
\text { being. carried but convention dictates that the Prime Minister will seek } \\
\text { an early dissolution of Parliament and a general election. If the Prime } \\
\text { Minister refused to seek dissolution, it would theoretically be open to the } \\
\text { Sovereign to dissolve Parliament on his or her own account, or to dismiss } \\
\text { the Government. This would represent a major breach of constitutional } \\
\text { convention unheard of in modem times. In } 1979 \text { the House carried a } \\
\text { motion of no confidence, moved by the then leader of the opposition, } \\
\text { Margaret Thatcher, by } 311 \text { votes to } 310 \text {. As a consequence the then Prime } \\
\text { Minister, James Callaghan, sought the dissolution of Parliament. At the } \\
\text { ensuing general election, the Conservative Party secured a majority of } \\
\text { seats in the House and Mrs. Thatcher was invited to form a Government. } \\
\text { Between } 1991 \text { and } 2004 \text {, six motions of censure were tabled: two motions } \\
\text { of no confidence in the Government, and four expressing criticisms of } \\
\text { ministers. All six were opposition motions, and none was agreed to by } \\
\text { the House. }\end{array}$ \\
\hline $\begin{array}{l}\text { Republica } \\
\text { Checa }\end{array}$ & $\operatorname{sim}$ & $\begin{array}{l}\text { The Chamber of Deputies may express no confidence in the government } \\
\text { (Article } 72 \text { of the Constitution). The reasons a no-confidence motion } \\
\text { are not specified./Modalities: A motion to express no confidence in } \\
\text { Government is considered by the Chamber of Deputies only if it is filed in } \\
\text { written form by no less then } 50 \text { deputies. The motion is carried when } 101 \\
\text { deputies vote in favour of it./Consequences: The government resigns if } \\
\text { the Chamber votes a no-confidence motion. If a motion of no confidence } \\
\text { is accepted, the Prime Minister submits his resignation to the President. } \\
\text { Other members of government submit their resignations to the President } \\
\text { through the Prime Minister. }\end{array}$ \\
\hline
\end{tabular}




\begin{tabular}{|c|c|c|}
\hline País & $\begin{array}{c}\text { moçáo de } \\
\text { censura }\end{array}$ & Observaçóes/efeitos e consequências a) \\
\hline Roménia & $\operatorname{sim}$ & $\begin{array}{l}\text { Both chambers may withdraw their confidence in the Government by } \\
\text { a vote of no confidence (Article } 113 \text { of the Constitution)./Modalities: } \\
\text { Both chambers, in joint session, may withdraw their confidence in the } \\
\text { Government by a majority vote of the deputies and senators. The motion } \\
\text { of censure may be initiated by at least one fourth of the total number of } \\
\text { deputies and senators, and shall be notified to the Government upon the } \\
\text { date of its tabling. The motion is debated and voted after three days have } \\
\text { elapsed from the date on which it was tabled before the joint session of } \\
\text { the chambers. If it is not carried, those deputies and senators who signed } \\
\text { it may not table a new vote of no confidence in the same session except } \\
\text { in the case where the Government engages its responsibility before the } \\
\text { parliament. /Consequences: The Government is dismissed from office } \\
\text { on the date the parliament withdraws its confidence. Between } 1992 \text { and } \\
2000 \text {, eight motions of no confidence were tabled by the opposition but } \\
\text { none was carried. }\end{array}$ \\
\hline Suécia & $\operatorname{sim}$ & $\begin{array}{l}\text { If Parliament declares that the Prime Minister, or any other minister, } \\
\text { no longer enjoys the confidence of Parliament, the Speaker discharges } \\
\text { the minister concerned (Article } 6 \text {, paragraph } 5 \text { of the Instrument of } \\
\text { Government). If Government is in a position to order an extraordinary } \\
\text { election, however, no decision to discharge the minister is announced, } \\
\text { provided Government calls an extraordinary election within one week } \\
\text { from the declaration of no confidence. A minister is discharged if he or } \\
\text { she so requests, that is, the Prime Minister is discharged by the Speaker, } \\
\text { and another minister by the Prime Minister. The Prime Minister may } \\
\text { also discharge another minister in other circumstances./Modalities: } \\
\text { A declaration of no confidence requires the concurrence of } 175 \\
\text { parliamentarians. A motion calling for a declaration of no confidence is } \\
\text { taken up for consideration only if raised by at least } 35 \text { parliamentarians. It } \\
\text { is not taken up for consideration during the period between the holding } \\
\text { of an ordinary election, or the announcement of a decision to call an } \\
\text { extraordinary election, and the date on which the new Parliament elected } \\
\text { in such an election convenes. A motion relating to a minister who has } \\
\text { remained at his post, after having been formally discharged, may not } \\
\text { in any circumstances be taken up for consideration. A motion calling } \\
\text { for a declaration of no confidence may not be prepared in committee./ } \\
\text { Consequences: If the Prime Minister is discharged or dies, the Speaker } \\
\text { discharges the other ministers. If all members of Government have been } \\
\text { discharged, they remain at their posts until a new Government has assumed } \\
\text { office. If a minister other than the Prime Minister has been discharged } \\
\text { at his or her own request, he or she remains in office until a successor } \\
\text { has assumed office, should the Prime Minister so request. Between } 1980 \\
\text { and } 2001 \text {, three motions of no confidence were tabled against the Prime } \\
\text { Minister, and one against the foreign minister. Three motions originated } \\
\text { from the opposition, one from governing parties, but none was accepted. }\end{array}$ \\
\hline
\end{tabular}




\begin{tabular}{|c|c|c|}
\hline País & $\begin{array}{l}\text { moçáo de } \\
\text { censura }\end{array}$ & Observaçóes/efeitos e consequências a) \\
\hline Turquia & $\operatorname{sim}$ & $\begin{array}{l}\text { A motion of censure may be tabled either on behalf of a political party or } \\
\text { by the signature of at least } 20 \text { deputies (Article } 99 \text { of the Constitution) } \\
\text { and may concern the entire Government or an individual minister./ } \\
\text { Modalities: A motion of censure is circulated in printed form to the } \\
\text { members within three days of its being tabled. Inclusion of a motion of } \\
\text { censure on the agenda is debated within ten days of its circulation. In this } \\
\text { debate, only one of the signatories to the motion, one deputy from each } \\
\text { political party, and the Prime Minister or one minister on behalf of the } \\
\text { Council of Ministers, may take the floor. Together with the decision to } \\
\text { include the motion of censure on the agenda, the date for debating it will } \\
\text { also be decided. However, the debate may not take place less than two } \\
\text { days after the decision to place it on the agenda and may not be deferred } \\
\text { for more than seven days. In the course of that debate, a motion of no } \\
\text { confidence with a statement of reasons tabled by deputies or parties, or } \\
\text { the request for a vote of confidence by the Council of Ministers, may } \\
\text { be put to the vote only after a full day has elapsed. In order to unseat } \\
\text { the Council of Ministers or a minister, an absolute majority of the total } \\
\text { number of members is required in the voting, in which only the votes } \\
\text { of no confidence are counted./Consequences: If a motion of censure is } \\
\text { adopted against the Council of Ministers, the entire Government resigns, } \\
\text { whereas if an individual minister is concerned, only the latter resigns from } \\
\text { office. A number of motions of censure were initiated between } 1990 \\
\text { and } 2000 \text {. While most of them were not put on the agenda, five were } \\
\text { ultimately tabled in the parliament. }\end{array}$ \\
\hline Ucrânia & $\operatorname{sim}$ & $\begin{array}{l}\text { The parliament may consider the issue of responsibility of the cabinet } \\
\text { and adopt a resolution of no confidence (Article } 87 \text { of the Constitution)./ } \\
\text { Modalities: The parliament may consider the issue of responsibility of } \\
\text { the cabinet on the proposal of not less than one-third of all deputies and } \\
\text { adopt a resolution of no confidence by the majority of all its members. The } \\
\text { issue of responsibility of the cabinet may neither be considered more than } \\
\text { once during one regular session, nor within one year of the approval of the } \\
\text { programme of activity of the cabinet./Consequences: The resignation and } \\
\text { adoption of a resolution of no confidence in the Prime Minister results in } \\
\text { the resignation of the entire cabinet (Article } 115 \text { of the Constitution). The } \\
\text { cabinet, whose resignation is accepted by the President, continues to exercise } \\
\text { its powers by commission of the President until a new cabinet commences } \\
\text { its operation but for no longer than } 60 \text { days. Between } 1996 \text { and } 2001 \text {, } \\
\text { two motions of censure were tabled in the parliament: in } 1998 \text { (within the } \\
\text { opposition) and in } 2001 \text { (partly within the opposition and partly within the } \\
\text { majority) but only the latter was accepted. }\end{array}$ \\
\hline USA & & \\
\hline
\end{tabular}

Fontes: Saalfeld (2000); Zovatto et al (2007) e PARLINE database. a) optou-se por não se fazer a traduçáo dos motivos, mecanismos e efeitos dos institutos de controlo, por se tratar de uma variedade muitas vasta de sistemas parlamentares, ou não, e que com certeza empobrecia os aspectos mais técnicos. 


\section{Tabela 6: tipo de moçáo/autor/efeito}

\begin{tabular}{|c|c|c|c|}
\hline \multirow[t]{6}{*}{$\begin{array}{l}\text { Censura ao } \\
\text { Governo }\end{array}$} & $\begin{array}{c}\text { Rejeiçáo Programa } \\
\text { Governo }\end{array}$ & Confiança ao Governo & Efeitos \\
\hline & & $\begin{array}{c}\text { 8/12/1977 do Governo } \\
\text { (PS) }\end{array}$ & Rejeitada \\
\hline & 12/2/1978 do PCP & & Rejeitada \\
\hline & 12/2/1978 do PPD/PSD & & Rejeitada \\
\hline & 14/9/1978 do PS & & Aprovada \\
\hline & 12/12/1978 do PCP & & Rejeitada \\
\hline 4/6/1979 do PCP & & & Rejeitada \\
\hline \multirow[t]{5}{*}{ 4/6/1979 do PS } & & & Aprovada \\
\hline & 18/8/1979 do PPD/PSD-CDS & & Rejeitada \\
\hline & $17 / 1 / 1980$ do PS & & Rejeitada \\
\hline & 17/1/1980 do PCP & & Rejeitada \\
\hline & & $\begin{array}{c}\text { 18/1/1980 do } \\
\text { Governo (PSD/CDS/ } \\
\text { PPM) } \\
\end{array}$ & Aprovada \\
\hline \multirow[t]{9}{*}{ 13/6/1980 do PCP } & & & Retirada \\
\hline & 23/1/1981 da FRS & & Rejeitada \\
\hline & 23/1/1981 do PCP & & Rejeitada \\
\hline & 23/1/1981 do MDP/CDE & & Rejeitada \\
\hline & & $\begin{array}{c}\text { 23/1/1981 do } \\
\text { Governo (PSD/CDS/ } \\
\text { PPM) } \\
\end{array}$ & Aprovada \\
\hline & 19/9/1981 do PCP & & Rejeitada \\
\hline & 19/9/1981 do MDP/CDE & & Rejeitada \\
\hline & 19/9/1981 da FSR & & Rejeitada \\
\hline & & $\begin{array}{c}\text { 19/9/1981 do } \\
\text { Governo (PSD/CDS/ } \\
\text { PPM) }\end{array}$ & Aprovada \\
\hline 26/2/1982 do PS & & & Rejeitada \\
\hline \multirow[t]{3}{*}{ 19/3/1982 do PCP } & & & Retirada \\
\hline & & $\begin{array}{c}\text { 24/6/1983 do Governo } \\
\text { (PS/PSD) }\end{array}$ & Aprovada \\
\hline & & $\begin{array}{c}\text { 14/2/1984 do Governo } \\
\text { (PS) }\end{array}$ & Aprovada \\
\hline
\end{tabular}




\begin{tabular}{|c|c|c|c|}
\hline $\begin{array}{l}\text { Censura ao } \\
\text { Governo }\end{array}$ & $\begin{array}{c}\text { Rejeiçáo Programa } \\
\text { Governo }\end{array}$ & Confiança ao Governo & Efeitos \\
\hline $\begin{array}{l}14 / 2 / 84 \text { do } \\
\text { CDS-PP }\end{array}$ & & & Rejeitada \\
\hline \multirow[t]{5}{*}{$\begin{array}{l}31 / 5 / 84 \text { do } \\
\text { CDS-PP }\end{array}$} & & & Retirada \\
\hline & 20/11/1985 do PS & & Rejeitada \\
\hline & 20/11/1985 do PCP & & Rejeitada \\
\hline & 20/11/1985 do MDP/CDE & & Rejeitada \\
\hline & & $\begin{array}{l}\text { 20/6/1986 do } \\
\text { Governo (PSD) }\end{array}$ & Aprovada \\
\hline \multirow[t]{3}{*}{ 3/4/1987 do PRD } & & & Aprovada \\
\hline & 28/8/1987 do PS & & Rejeitada \\
\hline & 28/8/1987 do PCP & & Rejeitada \\
\hline \multirow[t]{3}{*}{ 7/10/1989 do PS } & & & Rejeitada \\
\hline & 15/11/91 do PS & & Rejeitada \\
\hline & 15/11/91 do PCP & & Rejeitada \\
\hline $\begin{array}{l}\text { 14/10/1994 do } \\
\text { CDS-PP }\end{array}$ & & & Rejeitada \\
\hline \multirow[t]{3}{*}{ 21/1/1995 do PCP } & & & Retirada \\
\hline & 04/11/1999 do PSD & & Rejeitada \\
\hline & 04/11/1999 do BE & & Rejeitada \\
\hline $\begin{array}{l}1 / 7 / 2000 \text { do } \\
\text { CDS-PP }\end{array}$ & & & Rejeitada \\
\hline 21/9/2000 do PSD & & & Rejeitada \\
\hline \multirow[t]{4}{*}{$25 / 05 / 2001$ do BE } & & & Rejeitada \\
\hline & 17/4/2002 do PCP & & Rejeitada \\
\hline & $15 / 4 / 2002$ do BE & & Rejeitada \\
\hline & & $\begin{array}{c}\text { 18/4/2002 do Gverno } \\
\text { (PSD/PP) }\end{array}$ & Aprovada \\
\hline 26/3/2003 do PEV & & & Rejeitada \\
\hline 26/3/2003 do BE & & & Rejeitada \\
\hline 26/3/2003 do PCP & & & Rejeitada \\
\hline \multirow[t]{4}{*}{ 26/3/2003 do PS } & & & Rejeitada \\
\hline & 27/7/2004 do PS & & Rejeitada \\
\hline & 27/7/2004 do PCP & & Rejeitada \\
\hline & 27/7/2004 do PEV & & Rejeitada \\
\hline
\end{tabular}




\begin{tabular}{l|c|c|c}
\multicolumn{1}{c|}{$\begin{array}{c}\text { Censura ao } \\
\text { Governo }\end{array}$} & $\begin{array}{c}\text { Rejeiçáo Programa } \\
\text { Governo }\end{array}$ & Confiança ao Governo & Efeitos \\
\hline & $26 / 7 / 2004$ do BE & Rejeitada \\
\hline $04 / 06 / 2008$ do & & $\begin{array}{c}27 / 7 / 2004 \text { do Governo } \\
\text { (PSD/PP) }\end{array}$ & Aprovada \\
\hline CDS-PP & & & Rejeitada \\
\hline PCP & & & Rejeitada \\
\hline $11 / 01 / 2008$ do BE & & & Rejeitada \\
\hline $12 / 06 / 2009$ do & & & Rejeitada \\
\hline CDS-PP & & & Rejeitada \\
\hline $21 / 5 / 2010$ do PCP & & & \\
\hline
\end{tabular}

Fontes: Arquivo dos Diários da Assembleia da República (www.parlamento.pt) para o período de 1987 a 2010 e Matos, (1992) para o período de 1977 a 1987, construção própria. 
